\title{
Represión y vigilancia hacia el Trabajo Docente durante la Dictadura Militar en Chile (1973-1990)
}

\section{Repression and Vigilance towards Teaching Work during the Military Dictatorship in Chile (1973-1990)}

\author{
Felipe Andres Zurita Garrido ${ }^{1}$ \\ Universidad Academia de Humanismo Cristiano (Chile)
}

Recibido: 29-05-17

Aprobado: 10-07-17

\section{Resumen}

Este artículo tiene como objetivo analizar las políticas de represión y vigilancia ejercidas contra el Trabajo Docente durante la Dictadura Militar (1973-1990). Para alcanzar este objetivo se interrogan diferentes fuentes: Informes de Derechos Humanos, Actas de las Sesiones Secretas de la Junta Militar y documentos propios del funcionamiento cotidiano del aparato de represión. Allí, la figura de profesoras y profesores encuentra un lugar de destaque en tanto grupo a corregir y perseguir, situación que invita a sostener que la Dictadura Militar dedicó una especial atención hacía el Trabajo Docente, apoyándose en estrategias de vigilancia y persecución especialmente diseñadas para estas finalidades.

Palabras-clave: Represión, Vigilancia, Trabajo Docente, Dictadura Militar en Chile.

\footnotetext{
${ }^{1}$ (fzurita@academia.cl) Profesor de Historia y Ciencias Sociales (Universidad Academia de Humanismo Cristiano, Chile); Doctor en Educación (Universidad Federal de Minas Gerais, Brasil). Académico de la Escuela de Pedagogía en Historia y Ciencias Sociales de la Universidad Academia de Humanismo Cristiano. Algunas de sus publicaciones recientes son: ZURITA, F.: "Edward Palmer Thompson: historia, experiencia y formación para pensar la Historia de la Educación", en Cuadernos Chilenos de Historia de la Educación. n. 3, p. 8-33, 2015; ZURITA, F. "El sistema universitario en el Chile contemporáneo. Educação" em Revista, v. 31, n. 2, pp. 329-343, 2015; ZURITA, F. "Violencia, poder político y políticas públicas educacionales: el trabajo docente bajo la dictadura militar en Chile (1973-1990)", en Revista Teoria e Prática da Educação, v. 18, n. 1, pp. 89-100, 2015.
} 


\begin{abstract}
Our aims is to analyze the policies of repression and surveillance exercised against the Teaching Work during the Military Dictatorship (1973-1990). To reach this objective, they are questioned from different sources: Reports of Human Rights, Minutes of the Secret Sessions of the Military Junta and documents proper to the day-to-day operation of the repression apparatus. There, the figure of the teachers and professors stands out as an important group to correct and pursue; the situation that invites to one to maintain that the military dictatorship dedicated a special attention in the work of teachers, supporting in the strategies of monitoring and persecution especially designed for these purposes.
\end{abstract}

Key-words: Repression, Surveillance, Teaching Work, Military Dictatorship in Chile.

\title{
La violencia estatal bajo la Dictadura Militar (1973-1990)
}

La Dictadura Militar chilena llevó adelante un rápido y agresivo proceso de desarticulación y articulación institucional con el objetivo de asegurarse un amplio poder político mediante el uso abusivo e inconsulto de los diferentes espacios de decisión y representación democráticos. Una tarea paralela a esta dimensión institucional fue la de buscar destruir militarmente a los diferentes actores y grupos visualizados como potenciales opositores, y de paso, amedrentar al conjunto de la sociedad en los mismos términos, intentando con esto inhibir cualquier emergencia de posiciones de resistencia o cuestionamiento desde el interior de aquella. Lo llamativo de esto, es que para llevar adelante parte de esta tarea, la Dictadura Militar también utilizó la vía institucional, al diseñar e implementar una vasta legislación represiva, a saber: declaración del Estado de $\mathrm{Sitio}^{2}$; declaración del Estado de Emergencia ${ }^{3}$; legislación que establece la pena de exilio y la prohibición de retornar al país ${ }^{4}$; modificaciones a la Ley de

${ }^{2}$ CHILE. Decreto Ley N ${ }^{\circ} 3$ Declara Estado de Sitio. Ministerio de Defensa Nacional - Subsecretaria de Guerra, Santiago, 18 Septiembre 1973. Disponible en: http://bcn.cl/1rwzr Consultado en: 14 Julio 2015.

${ }^{3}$ CHILE. Decreto Ley $\mathrm{N}^{\circ} 4$ Declara en Estado de Emergencia las Provincias y Departamentos que indica. Ministerio de Defensa Nacional - Subsecretaria de Guerra, Santiago, 18 Septiembre 1973. Disponible en: http://bcn.cl/1rx13 Consultado en: 14 Julio 2015.

${ }^{4}$ CHILE. Decreto Ley $N^{\circ} 81$ Fija, por razones de seguridad del estado, sanciones; para las personas que desobedezcan el llamamiento; público que indica del gobierno. Ministerio de Defensa Nacional Subsecretaria de Guerra, Santiago, 06 Noviembre 1973. Disponible en: http://bcn.cl/1yjo5 Consultado en: 14 Julio 2015; CHILE. Decreto Ley N 604 Prohíbe el ingreso de personas al territorio nacional en los casos que indica. Ministerio del Interior, Santiago, 10 Agosto 1974. Disponible en: http://bcn. cl/1weka Consultado en: 14 Julio 2015. 
Seguridad del Estado ${ }^{5}$; modificaciones a la Ley de Control de Armas ${ }^{6}$; dictación de la Ley de Amnistía ${ }^{7}$; dictación de la Ley Antiterrorista ${ }^{8}$; entre otras. Toda esta legislación tuvo en común el objetivo de legitimar jurídicamente la persecución y el castigo dirigido hacia opositores de la Dictadura Militar, generando un espacio de nuevas posibilidades de represión dentro de la estructura jurídica nacional, las que facilitaron la ampliación de la violencia estatal en un contexto de profunda degradación de los equilibrios democráticos y amplia impunidad.

La nueva legislación represiva abrió la puerta a un vendaval de violencia estatal contra enemigos políticos específicos y contra la sociedad chilena en su conjunto. Ciertamente, al abordar la violencia estatal en Chile no es adecuado sostener perspectivas ingenuas, tales como que la misma hubiese sido inaugurada por la Dictadura Militar que aquí se aborda, por el contrario, existen muchos antecedentes históricos que muestran como la violencia estatal, o la violencia política por el control del Estado, han jugado un papel de primera importancia en la experiencia histórica de Chile 9 . No obstante lo anterior, es en la Dictadura Militar cuando la violencia estatal asume una dimensión profundamente protagónica en la administración de las acciones y conflictos del Régimen, ya sea en sus medios, finalidades y fundamentos.

Siguiendo la idea anterior, a pesar de la existencia de una compleja legislación represiva construida por la propia Dictadura Militar, caracterizada por tener amplios límites y difusos contornos, la violencia estatal sobrepasó largamente a todo lo prescrito y surcó la geografía nacional de manera brutal, acrecentando la máscara del Terrorismo de Estado ${ }^{10}$ como una de las facetas

${ }^{5}$ CHILE. Decreto $N^{\circ} 890$ Fija texto actualizado y refundido de la Ley 12.927, sobre Seguridad del Estado. Ministerio del Interior, Santiago, 26 Agosto 1975. Disponible en: http://bcn.cl/1v181 Consultado en: 14 Julio 2015.

${ }^{6}$ CHILE. Decreto $N^{\circ} 400$ Fija texto refundido, coordinado y sistematizado de la Ley $\mathrm{N}^{\circ} 17.798$, sobre control de armas. Ministerio de Defensa Nacional, Santiago, 13 Abril 1978. Disponible en: http://bcn.cl/1v2mw Consultado en: 14 Julio 2015.

${ }^{7}$ CHILE. Decreto Ley $N^{\circ} 2.191$ Concede amnistía a las personas que indica por los delitos que señala. Ministerio del Interior, Santiago, 19 Abril 1978. Disponible en: http://bcn.cl/1v3xd Consultado en: 14 Julio 2015.

${ }^{8}$ CHILE. Ley $\mathrm{N}^{\circ} 18.314$ Determina conductas terroristas y fija su penalidad. Ministerio del Interior, Santiago, 17 Mayo 1984. Disponible en: http://bcn.cl/1v1bp Consultado en: 14 Julio 2015.

9 Ver: Manns, P. Las grandes masacres. Santiago: Editora Nacional Quimantú, 1972. 95 p.; GARCÉS, M. Crisis social y motines populares en el 1900. Santiago: Lom, 2003. 258 p.

${ }^{10}$ Siguiendo la perspectiva de Ernesto Garzón Valdés (1989), por Terrorismo de Estado se entenderá aquí a un tipo específico de sistema político cuyos aspectos más representativos son: a) la aplicación de severas medidas coercitivas que sobrepasan ampliamente la legalidad vigente asumiendo así un perfil de violencia estatal clandestina e ilegal; b) direccionar la violencia estatal contra una parte de la población que es difícil de identificar con precisión, que es acusada de ser un enemigo interno que se distribuye por toda la extensión de la sociedad, que amenaza los valores defendidos por las autoridades que poseen el poder político y que sería merecedor del despliegue de toda la fuerza destructiva del Estado en su contra; c) generar condiciones políticas para evitar el funcionamiento adecuado del sistema judicial, situación que favorece una acción del Gobierno ilimitada en la búsqueda de la ampliación/mantenimiento de su poder, gozando el mismo de una abierta condición de impunidad en su actuar. Garzón, E. "El terrorismo de Estado. (El problema de su legitimación e ilegitimidad)", en Revista de Estudios Políticos, Madrid, n. 65, p. 35-55, Julio-Septiembre 1989. 
más visibles del Estado de Chile durante este periodo. Planteado así, la sociedad chilena en su conjunto comenzó a convivir durante la Dictadura Militar con las prácticas propias del Terrorismo de Estado, a saber: asesinatos; desapariciones forzadas; torturas; violencia sexual; detenciones injustificadas; vigilancia y amedrentamiento; prisión política; secuestros; confinamientos; allanamientos; exilio; entre otras, cometidas por diferentes agentes del Estado y también por particulares simpatizantes del Régimen.

Un perfil de Fuente adecuada para intentar dimensionar el impacto del Terrorismo de Estado durante la Dictadura Militar en la sociedad chilena corresponde a los diferentes Informes de Derechos Humanos ${ }^{11}$ construidos en la Post-Dictadura. En estos, la presencia del Trabajo Docente es bastante importante. Pamela Sánchez (2013) realizó el trabajo de identificar a Profesoras y Profesores en los registros de los Informes de Derechos Humanos, eso sí, sosteniendo una comprensión amplía sobre quiénes integrarían el Trabajo Docente:

\begin{abstract}
"Buscando recopilar una nómina que se acerque más a la realidad educacional chilena del periodo contemplado, se han considerado profesores y profesoras a aquellas personas que trabajaron como docentes, en cualquier nivel educativo, también a los que fueron estudiantes de pedagogía y a los que sin ejercer la docencia tenían el título de profesores. Esta recopilación contempla profesores básicos, normalista, universitarios, parvularios profesionales y técnicos que ejercían docencia y los que sin tener título de profesores, enseñaban" (Sánchez, 2013, p. 11).
\end{abstract}

Considerando dicha opción asumida, el resultado de la investigación de Pamela Sánchez (2013) arrojó el impresionante registro de 64 Profesoras y Profesores Detenidos Desaparecidos y 70 Detenidos Ejecutados. Una aproximación al ejercicio de dibujar el perfil de estas personas es posible de ser presentada en el siguiente cuadro:

11 COMISIÓN NACIONAL DE VERDAD Y RECONCILIACIÓN. Informe de la Comisión Nacional de Verdad y Reconciliación. Santiago: Secretaria General de Gobierno - Secretaría de Comunicación y Cultura, 1991, 2 Tomos 3 Volúmenes; CORPORACIÓN NACIONAL DE REPARACIÓN Y RECONCILIACIÓN. Informe Sobre Calificación de Victimas de Violaciones de Derechos Humanos y de la Violencia Política. Santiago: La Corporación, 1996. 635 p.; COMISIÓN NACIONAL SOBRE LA PRISIÓN POLÍTICA Y TORTURA. Informe de la Comisión Nacional Sobre la Prisión Política y Tortura. Santiago: La Comisión, 2005. 777 p.; COMISIÓN PRESIDENCIAL ASESORA PARA LA CALIFICACIÓN DE DETENIDOS DESAPARECIDOS, EJECUTADOS POLÍTICOS Y VÍCTIMAS DE PRISIÓN POLÍTICA Y TORTURA. Informe de la Comisión Presidencial Asesora para la Calificación de Detenidos Desaparecidos, Ejecutados Politicos y Victimas de Prisión Política y Tortura. Santiago: La Comisión, 2011. 55 p. 
Tabla I: Perfil Profesoras y Profesores Detenidos

Desaparecidos y Detenidos Ejecutados (1973-1990)

\begin{tabular}{|c|c|c|c|}
\hline \multicolumn{2}{|c|}{ CARACTERÍSTICAS } & \multirow{2}{*}{ 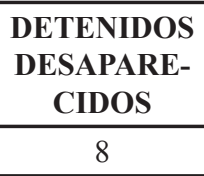 } & \multirow{2}{*}{$\begin{array}{c}\text { DETENIDOS } \\
\text { EJECUTADOS } \\
8 \\
\end{array}$} \\
\hline Sexo & Mujer & & \\
\hline & Hombre & 56 & 62 \\
\hline \multirow[t]{4}{*}{ Edad } & Entre 20 y 29 años & 28 & 28 \\
\hline & Entre 30 y 39 años & 20 & 29 \\
\hline & Entre 40 y 49 años & 13 & 12 \\
\hline & 50 años o más & 3 & 1 \\
\hline \multirow[t]{2}{*}{$\begin{array}{l}\text { Militancia } \\
\text { Política }\end{array}$} & $\begin{array}{l}\text { Militancia Política } \\
\text { conocida }\end{array}$ & 55 & 57 \\
\hline & $\begin{array}{l}\text { Militancia Política } \\
\text { desconocida }\end{array}$ & 9 & 13 \\
\hline \multirow[t]{2}{*}{ Nacionalidad } & Chilena & 61 & 67 \\
\hline & Extranjera & $3^{1}$ & $3^{2}$ \\
\hline \multirow{10}{*}{$\begin{array}{l}\text { Fecha } \\
\text { Detención y } \\
\text { Desaparecimiento } \\
\text { o Detención } \\
\text { y Ejecución }\end{array}$} & 1973 & 27 & 44 \\
\hline & 1974 & 21 & 5 \\
\hline & 1975 & 6 & 8 \\
\hline & 1976 & 9 & 2 \\
\hline & 1979 & & 2 \\
\hline & 1980 & & 1 \\
\hline & 1981 & 1 & 2 \\
\hline & 1984 & & 2 \\
\hline & 1985 & & 2 \\
\hline & 1986 & & 2 \\
\hline \multirow{3}{*}{$\begin{array}{l}\text { Lugar } \\
\text { Detención y } \\
\text { Desaparecimiento } \\
\text { o Detención } \\
\text { y Ejecución }\end{array}$} & Santiago & 33 & 24 \\
\hline & Regiones & 29 & 44 \\
\hline & Fuera de Chile & 2 & 2 \\
\hline
\end{tabular}

Fuente: Sánchez, P. Una asignatura pendiente: profesores y profesoras detenidos/ as desaparecidos/as y ejecutados/as en Chile de 1973 a 1990. Santiago: Editorial Arcis, 2013. 423 p. 
Puesta la información de esta manera, el perfil más representativo de las víctimas del Terrorismo de Estado ejercido por la Dictadura Militar hacia los integrantes del Trabajo Docente estaría compuesto por las siguientes características: ser mayoritariamente hombres jóvenes y de mediana edad; sostener una militancia política abiertamente reconocida; ser en su mayoría de nacionalidad chilena; ser desaparecidos y ejecutados de forma mayoritaria en los primeros momentos de existencia de la Dictadura Militar (1973-1974) y de manera más recurrente en la ciudad de Santiago. De esta forma, siguiendo la lógica de identificar las más graves violaciones a los Derechos Humanos cometidas por la Dictadura Militar contra los integrantes del Trabajo Docente, es posible sostener una línea de continuidad con el perfil de las demás víctimas del Terrorismo de Estado pertenecientes a otros grupos laborales: ser personas que, por diferentes circunstancias de la vida, de manera directa o indirecta, se habrían vinculado a proyectos políticos orientados hacia la búsqueda de la transformación social y que se desenvolvían en los más diferentes espacios de la vida económica, social o cultural. Así planteado, no hay que dejar de mencionar que evidentemente el poder prepotente y avasallador del Terrorismo de Estado fue mayoritaria e intencionalmente orientado hacia los integrantes de los Partidos Políticos de izquierda, fuesen o no integrantes de la Unidad Popular. El poder destructor de la Dictadura Militar no fue ciego ni dejado al azar. La adscripción política a proyectos de corte transformador fue asumida por la Dictadura Militar como una afronta insoportable, tanto así que la misma significó para muchas y muchos docentes la justificación esgrimida para dar fin a su existencia.

\section{Vigilancia y persecución hacia el Profesorado}

El Terrorismo de Estado, articulado y dirigido por la Dictadura Militar hacía el Trabajo Docente, no incluyó solamente las estrategias de más graves violaciones a los Derechos Humanos, tales como el desaparecimiento y ejecución de personas ya abordados. La imaginación represiva proveyó a la Dictadura Militar de otras formas más sutiles para castigar y vigilar a potenciales opositores políticos dentro de las filas del profesorado.

La vigilancia constante se constituyó en una herramienta de uso cotidiano para conocer y administrar políticamente a los integrantes del Trabajo Docente. El Ministro de Educación Pública, Contraalmirante Hugo Castro Jiménez, según registros del Acta $N^{\circ} 160$ A de la Sesión Secreta de la Junta Militar de Gobierno del día 08 de Octubre de 1974, asumió abiertamente el activo papel que cumplía el trabajo de "Inteligencia" como uno más de los diferentes actores que influían en el sistema educacional chileno: 


\begin{abstract}
"También tiene incidencia la parte seguridad del país. La Inteligencia está permanentemente funcionando, dando datos, indicando que hay que sacar a determinado profesor, que hay que poner a otro, etc. El Ejército coopera mucho; Carabineros en menor escala; la Armada y la FACH también tienen delegados y en algunas provincias tienen más cantidad de gente que el Ejército; pero el Ejército a través de los Intendentes influye bastante" (Junta de Gobierno, 1974, p. 2$)^{12}$.
\end{abstract}

La vigilancia, orientada fundamentalmente a la tarea de identificación de opositores políticos de la Dictadura Militar, obtuvo una dimensión de primera importancia, impregnando la orientación de diferentes tareas al interior del Régimen. A modo de ejemplo, en la Sesión Secreta de la Junta Militar de Gobierno del día 11 de Octubre de 1978, el General Fernando Matthei Aubel llegó a cuestionar que el trabajo legislativo de la misma Junta Militar de Gobierno fuese utilizado como una vía para expurgar a opositores políticos por vía legal, frente a la presentación de un Proyecto de Ley que buscaba dejar en calidad de interinato a todos los funcionarios públicos de las Municipalidades de la V Región de Valparaíso, debido a la supuesta presencia de opositores políticos a la Dictadura Militar entre sus filas:

\begin{abstract}
"El señor GENERAL MATTHEI, MIEMBRO DE LA JUNTA.- Me gustaría discutirlo un poco. Estoy de acuerdo en que, en general, en las municipalidades hay que pasar la escoba. Ahora, no estoy tan convencido acerca del método que se emplearla. Considero que ni el interinato es lo que aquí vale. Además, hay otras formas de proceder, o podría haber otras fórmulas, como incluso lo señala en este momento el señor Ministro. El problema que diviso es que aquí, para limpiar un problema en una municipalidad, en el fondo estamos usando el Poder Legislativo. Nosotros estamos asumiendo la responsabilidad de un problema político local. Me da la impresión, no sé, de que nos estamos empleando nosotros políticamente a un nivel muy pequeño, y eso es lo que me preocupa en este asunto. A mi juicio, hay funciones de otras autoridades que fracasaron y fallaron en limpiar sus municipalidades, y, entonces, asume la Junta de Gobierno la responsabilidad" (Junta de Gobierno, 1978, p. 21) ${ }^{13}$.
\end{abstract}

El cuestionamiento presentado por el General Fernando Matthei Aubel no estaba orientado a poner en duda la validez de la vigilancia y persecución a trabajadoras y trabajadores por cuestiones políticas. Lo que molestaba, era la escala de la vigilancia y persecución política, o sea, el hecho de que la mismísima Junta Militar de Gobierno tuviese que hacerse cargo de tareas sancionadoras de tan pequeña dimensión, en tanto, para aquello existirían otras autoridades y herramientas a ser movilizadas.

12 JUNTA DE GOBIERNO. Actas Junta de Gobierno. Santiago, Acta N 160 A, Sesión Secreta 08 Octubre 1974. Página 2.

${ }^{13}$ JUNTA DE GOBIERNO. Actas Junta de Gobierno. Santiago, Acta N ${ }^{\circ} 355$ A, Sesión Secreta 11 Octubre 1978. Página 21.

Araucaria. Revista Iberoamericana de Filosofia, Política y Humanidades, año 19, n 38 . Segundo semestre de 2017. Pp. 285-322. ISSN 1575-6823 e-ISSN 2340-2199 doi: 10.12795/araucaria.2017.i38.13 
Sin embargo, el problema de la escala de la vigilancia y persecución política no siempre fue una dificultad para los integrantes de la Junta Militar de Gobierno, puesto que en el análisis de las Actas de las Sesiones Secretas de la misma, aparecen reiteradas alusiones al caso de un Establecimiento Educacional específico, como un foco de las atenciones al más alto nivel. Se trató del Saint George's College, Establecimiento Educacional Particular Pagado ubicado en un barrio acomodado de la ciudad de Santiago, administrado por la Congregación de Santa Cruz y reconocido por ser un espacio de formación escolar de elite. Parte de las autoridades del Saint George's College habrían adscrito al ambiente de transformaciones político/sociales impulsado por el Gobierno de la Unidad Popular, implementando un proceso de apertura y democratización interna de sus lógicas de funcionamiento, objetivo que se reflejó de manera más clara en la incorporación de estudiantes de origen popular dentro de sus muros ${ }^{14}$. Muy probablemente, esta situación permite comprender el especial interés que despertó este Establecimiento Educacional al interior de la Junta Militar de Gobierno, que una vez desatado el Golpe de Estado, intervino al mismo y separó de sus funciones al Rector Gerardo Whelan. A sólo diez días después del Golpe de Estado aparece por primera vez mencionado el Saint George's College en las Actas de las Sesiones Secretas de la Junta Militar de Gobierno:
“3.- Se informa al Sr. M.D.M. sobre situación de cinco sacerdotes del Colegio Saint George que serían marxistas. Se acuerda declararlos personas no gratas y ponerlos a disposición de su embajada" (Junta de Gobierno, 1973, p. 1) $)^{15}$.

Al paso de unos días, con un Delegado Militar ya instalado en la administración del Saint George's College, el Ministro de Educación Pública, Contraalmirante Hugo Castro Jiménez, informa a la Junta Militar de Gobierno sobre el avance de las gestiones para sancionar a determinados actores de dicha institución:

\begin{abstract}
“Actividad del Delegado Militar en el Colegio Saint-George ante denuncias de apoderados sobre intervención marxista de algunos sacerdotes y profesores y reacción del Secretario Provincial U.S.A. del Sector Estudiantil, quien ha estado realizando una acción dilatoria. La proposición del Ministro de Educación es remover a los sacerdotes extranjeros y hacerlos volver a su país y trasladar a los profesores chilenos, haciendo presente que existen presunciones de que esto no será aceptado por la Congregación, la que tendría previsto retirarse del país
\end{abstract}

14 Todo ese proceso de transformaciones y tensiones al interior del Saint George's College fue trabajado en la película "Machuca" (2004) del Director chileno Andres Wood, ex alumno de dicha institución y testigo privilegiado de dicho contexto.

15 JUNTA DE GOBIERNO. Actas Junta de Gobierno. Santiago, Acta N 7, Sesión Secreta 21 Septiembre 1973. Página 1.

Araucaria. Revista Iberoamericana de Filosofía, Política y Humanidades, año 19, no 38. Segundo semestre de 2017. Pp. 285-322. ISSN 1575-6823 e-ISSN 2340-2199 doi: 10.12795/araucaria.2017.i38.13 
con gran publicidad. Se acuerda que el Ministro de Educación se entreviste con el Embajador de Estados Unidos, quien ha ofrecido sus buenos oficios para solucionar en forma conveniente este impase" (Junta de Gobierno, 1973, p. 2) ${ }^{16}$.

En la Sesión Secreta de la Junta Militar de Gobierno del 08 de Febrero de 1974, el Ministro de Educación Pública, Contraalmirante Hugo Castro Jiménez, realiza la siguiente mención a la situación de los sacerdotes de la Congregación de Santa Cruz, al parecer, ya fuera de Chile:

“e) Con respecto al Colegio Saint-George, expresa; que la congregación durante

el presente año no volverá" (Junta de Gobierno, 1974, p. 3) ${ }^{17}$.

La atención pormenorizada que dirigió la Dictadura Militar hacia el Saint George's College muestra que, finalmente, la escala de trabajo en las tareas de vigilancia y persecución incluyó a comunidades educacionales específicas y puntuales, mostrando un cierto interés por copar los diferentes espacios escolares tras la identificación y sanción a actores identificados como potenciales opositores políticos.

Otro ejemplo de esta amplía importancia de la vigilancia y persecución política a opositores dentro de las diferentes áreas de trabajo de la Dictadura Militar se encuentra en la forma en que habría sido utilizada la implementación de la Ley de Carrera Docente (1978-1981) ${ }^{18}$. En la Sesión Secreta de la Junta Militar de Gobierno del día 24 de Abril de 1980, el Ministro de Educación Pública, Alfredo Prieto Bafalluy, entregó argumentos al General Augusto Pinochet Ugarte, defendiendo la necesidad de que fuesen aprobadas algunas modificaciones a la Ley de Carrera Docente con miras a facilitar el despido de determinado perfil de profesoras y profesores:

"EL GENERAL PINOCHET, PRESIDENTE DE LA REPUBLICA. (No se entiende el comienzo de la frase)... usted se está preparado para el futuro. EL señor PRIETO, MINISTRO DE EDUCACION,- Exactamente. Si me permite, señor Presidente, quiero señalar que la facultad de desburocratización, que la estamos usando en el Ministerio para algunos casos, puede ser puntual, porque yo no puedo sacar a 1,000 profesores con esta facultad, pero sí puedo utilizar esta herramienta para la reducción de jornada; tomar a aquellos cuya labor, hoy día, es nada más que hacer activismo en contra del Gobierno por nuestro sistema educacional. Es una facultad que debemos usar, porque

${ }^{16}$ JUNTA DE GOBIERNO. Actas Junta de Gobierno. Santiago, Acta № 25, Sesión Secreta 24 Octubre 1973. Página 2.

17 JUNTA DE GOBIERNO. Actas Junta de Gobierno. Santiago, Acta № 88, Sesión Secreta 08 Febrero 1974. Página 3.

${ }^{18}$ CHILE. Decreto Ley N ${ }^{\circ} 2.327$ Crea la Carrera Docente y regula su ejercicio. Ministerio de Educación Pública, Santiago, 22 Septiembre 1978. Disponible en: http://bcn.cl/3i2a Consultado en: 14 Julio 2015. 
estamos cometiendo un haraquiri con nuestro campo de la educación. Quiero señalar, a título de ejemplo, que tengo aquí en mi poder, determinados en lista, hechos de trabajo detectados con el servicio de inteligencia de toda institución, fundamentalmente, el C.N.I. y comprobados, respecto solamente a profesores que realizan actividades, excluyo a todo aquel profesor que no sea marxista, sino solamente clasificados entre comunistas, socialistas, miristas y marxistas; he excluido a todos los que son demócratas y que están en contra del Gobierno, y dentro de esos, sólo aquellos que están realizando activismo en contra del Gobierno en la sala. Es una lista por región y por escuela que sobrepasa los 3 mil a 4 mil profesores. Esa gente no la podemos tener dentro del sistema y para mí, el no tener esta facultad del titulado, me amarra las manos para poder, de alguna manera, tomar medidas con ellos. Esos son datos que tiene el C.N.I., que tienen los dirigentes..." (Junta de Gobierno, 1980, p. 52-53) ${ }^{19}$.

En las palabras del Ministro de Educación Pública, Alfredo Prieto Bafalluy, es posible visualizar de manera explícita la utilización de la Ley de Carrera Docente como una herramienta para vigilar y perseguir por cuestiones políticas al profesorado. Lo interesante de las palabras del Ministro de Educación Pública es que revelan que, para la realización de estas tareas, tuvo a disposición técnicas de catalogación de docentes según actividades y adscripciones de orden políticas, confeccionadas por el aparato de represión a nivel nacional. De esta forma, es posible sostener que el Trabajo Docente fue objeto de estudio del aparato de represión de la Dictadura Militar de manera extensa, puesto que, al parecer, el ojo y oído escrutador y vigilante del Régimen tuvo la capacidad de abarcar los Establecimientos Educacionales a lo largo y ancho del país. Para el Almirante José Toribio Merino, la utilización de los intersticios de la Ley de Carrera Docente con fines represivos a corto plazo, se justificaría (en tanto medio) para consolidar el siguiente perfil dentro del profesorado (en tanto objetivo):
"EL ALMIRANTE MERINO, MIEMBRO DE LA JUNTA.- Yo creo que el problema inmediato es resolver siete años que se ha estado tratando de solucionarlo y no se ha resuelto. Esta ley, aunque mala, es preferible que tenga aplicación por un plazo de un o dos años y que se estudie cómo, en el futuro, dejar al Ministerio las facultades para permanentemente poder mantener un grupo sano, homogéneo y capaz de enfrentar la educación en Chile" (Junta de Gobierno, 1980, p. 54) ${ }^{20}$.

La disposición de sofisticadas herramientas para la implementación de la vigilancia y la persecución política al profesorado resulta importante de

\footnotetext{
19 JUNTA DE GOBIERNO. Actas Junta de Gobierno. Santiago, Acta N 392 A, Sesión Secreta 24 Abril 1980. Página 52-53.

${ }^{20}$ JUNTA DE GOBIERNO. Actas Junta de Gobierno. Santiago, Acta N`392 A, Sesión Secreta 24 Abril 1980. Página 54.
} 
destacar aquí, puesto que incluso incluyó técnicas de orden sociológicas de procesamiento y medición de la tensión social al interior del Trabajo Docente. En la Sesión Secreta de la Junta Militar de Gobierno del 16 de Diciembre de 1986, el Almirante José Toribio Merino advirtió sobre el advenimiento de "situaciones relativamente dificiles":

"El señor ALMIRANTE MERINO.- Quisiera hacer presente una cosa. La situación del profesorado, en este momento, es en espera de esto. Este texto ha estado dándose vueltas entre nosotros aquí, prácticamente, todo el año y se espera para 1987, a más tardar en marzo, situaciones relativamente difíciles, tanto en el estudiantado como en el profesorado, por múltiples razones. Tengo informaciones que puedo darlas a conocer a la Junta y al respecto le cedo la palabra al Comandante Marinovic para que se refiera a ello" (Junta de Gobierno, 1986$, p. 7$)^{21}$.

La alarma del Almirante José Toribio Merino, con respecto al potencial aumento de la tensión social entre el estudiantado y docentes, iba sustentada en la presentación de una investigación realizada por parte de la Oficina de Estudios Sociológicos de la Armada a cargo del Capitán de Fragata Milán Marinovic, quien tomó la palabra de la siguiente manera:

"El señor COMANDANTE MARINOVIC.- Dentro del análisis de tensión social que hace la Oficina de Estudios Sociológicos, están los climas de tensión social y los procesos de desestabilización de la psico-política. Para esto, desde mayo del año 1983 a la fecha, se diseñaron indicadores en coordinación con el Ministerio del Interior, donde día a día se recibe por télex información de lo que ocurre en las regiones" (Junta de Gobierno, 1986, p. 7-8)22.

De esta manera, a través de las palabras del Capitán de Fragata Milán Marinovic, es posible advertir la existencia de un sistema de procesamiento y clasificación de eventos disruptivos desde la perspectiva de la Dictadura Militar, encuadrados en un esquema de vaivenes de la tensión social según épocas del año, lo que en última instancia, podría generar información valiosa para adelantarse y prepararse frente a los mismos. En esta misma línea, el Capitán de Fragata Milán Marinovic presentó a los integrantes de la Junta Militar de Gobierno la siguiente lectura sobre el estado de la tensión social en los últimos años, advirtiendo en dicha lectura que, en el contexto de una tendencia de declinación de la tensión social, se visualizaba en el profesorado la posibilidad de un proceso de anticipación/desarrollo de la misma:

${ }^{21}$ JUNTA DE GOBIERNO. Actas Junta de Gobierno. Santiago, Acta № 40, Sesión Secreta 16 Diciembre 1986. Página 7.

${ }^{22}$ JUNTA DE GOBIERNO. Actas Junta de Gobierno. Santiago, Acta № 40, Sesión Secreta 16 Diciembre 1986. Página 7-8. 
“Al hablar de tensión social hay que diferenciar cuál es la leña y cuál es el fuego, qué se manipula y qué se expresa en conducta. Sobre la base de ello, aquí están los indicadores de terrorismo, que muestran una tendencia desde mayo del 83 a la fecha, lo cual se ha predicho en pronósticos situacionales que oportunamente se entregan a la Presidencia y al Ministerio. También aquí está el activismo político que, igualmente, muestra una tendencia y que ha sido predecible por método... (no se entiende). Cuando uno divide la tensión, la manipulación por lo que se expresa tiene un factor de tensión social y este es el cuadro respectivo donde vemos que la energía se ha ido desgradando y en este momento es un proceso de desgradación de tensión social. Esto nos muestra que para el período 85-86 hay una idéntica desgradación, pero con adelanto de fase. Vale decir, que la desgradación de este año comenzó a partir del atentado presidencial y hallazgo de armas y en este instante estamos en la fase de desgradación o un adelanto en esta fase, que, tradicionalmente, ocurría en diciembre. Ahora, en el período de análisis, se distinguen tres fases: una, de gestación, que parte en marzo, con el inicio de clases; un período de madurez, que tradicionalmente parte en septiembre; y una etapa de baja, que culmina en diciembre. Entonces, en este momento se prevé un cambio de fase, un adelanto, pero esto hace sensible la manipulación del sector del profesorado, como

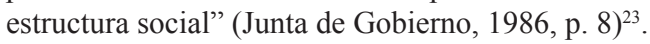

No obstante lo anterior, por qué podría ocurrir dicho movimiento de aumento de la tensión social en la percepción y actuación política del profesorado en un contexto mayor de aparente declinación general de la tensión social. La respuesta del Capitán de Fragata Milán Marinovic apunta a lo que llama como "manipulación de la situación del profesorado":

"Se identifican tres elementos como determinantes en la baja de tensión social: la seguridad económica avalada por la aprobación de crédito fiscal por la banca internacional y los indicadores económicos positivos; la solidaridad social, motivada por las festividades navideñas y el rechazo provocado por la violencia y el terrorismo; y el progreso político al consolidarse avances de leyes constitucionales en el proceso de transición. Y se identifica como factores sensibles, la manipulación de la situación del profesorado y entre ellas, la situación del profesorado en relación al no pago de reajuste similar al otorgado al sector público; despido masivo de, profesores sin título, aproximadamente, 11 mil; exoneración de profesores del Ministerio de Educación sin indemnización ni derechos, aproximadamente 500; exoneración de profesores que se prevé ocurrirá en las municipalidades por ajustes económicos ante déficit presupuestario; y expectativas creadas en torno al estatuto docente. Todo esto se ve como elementos susceptibles de explotación y que ya está partiendo, como se vio en el editorial de hace dos días atrás, sobre la Educación" (Junta de Gobierno, 1986, p. 8-9) ${ }^{24}$.

${ }^{23}$ JUNTA DE GOBIERNO. Actas Junta de Gobierno. Santiago, Acta N ${ }^{\circ} 40$, Sesión Secreta 16 Diciembre 1986. Página 8.

${ }^{24}$ JUNTA DE GOBIERNO. Actas Junta de Gobierno. Santiago, Acta N ${ }^{\circ} 40$, Sesión Secreta 16 Diciembre 1986. Página 8-9. 
La presentación de este estudio sobre la tensión social con respecto al profesorado a finales del año 1986 se inscribió en el contexto de discusión legislativa sobre el Proyecto de Ley de Estatuto del Profesor. Frente a los resultados expuestos por el Capitán de Fragata Milán Marinovic, el Almirante José Toribio Merino Castro hizo un llamado a la Junta Militar de Gobierno y a sus respectivas Comisiones Legislativas para aprobar en el corto plazo dicho Proyecto de Ley. De esta forma, aparece nuevamente esa hermandad entre el trabajo habitual de la Dictadura Militar, en este caso específico el trabajo legislativo, y el trabajo de vigilancia y persecución al profesorado, plasmado de manera clara en la utilización de una sofisticada herramienta teórico/ metodológica orientada al procesamiento de información y la medición de la tensión social al interior del Trabajo Docente.

\title{
El fenómeno de la delación
}

Otro mecanismo utilizado por la Dictadura Militar para encaminar sus tareas de vigilancia y persecución política hacía el profesorado corresponde al fenómeno de delación. Esta tuvo muchas caras, una es la que fue incentivada o incitada por la misma Dictadura Militar. Ya en el Bando $\mathrm{N}^{\circ} 1$, del mismo 11 de Septiembre de 1973, se hacía un abierto llamado a denunciar a personas que cometieran algún tipo de sabotaje:

\begin{abstract}
"Se advierte a los ciudadanos que cualquier acto de sabotaje en todo tipo de actividades nacionales, en empresas, fábricas, medios de comunicación o transporte, etc., será sancionado en la forma más drástica posible, en el lugar mismo del hecho sin otra limitación que no sea la determinación de las autoridades del caso, del o los responsables. El deber de la ciudadanía consciente, es respetar el patrimonio del país, denunciando en forma inmediata a quienes pretendan paralizar las actividades productoras y laborales de cualquier tipo" (Junta Militar de Gobierno, 1973, p. 1).
\end{abstract}

En el Bando $\mathrm{N}^{\circ} 26$ del 12 de Septiembre de 1973, la Junta Militar de Gobierno realizó una sucinta descripción de diferentes lugares ocupados y allanados en la ciudad de Santiago, en los que se habría encontrado armamento y "extremistas" que pondrían en peligro la seguridad nacional. Lo interesante es que se dedicó un párrafo completo para agradecer a las personas que habrían entregado informaciones valiosas para identificar aquellos espacios y sujetos:

"Las FF.AA., Carabineros e Investigaciones se hacen un deber agradecer de forma especial la patriótica actitud de la ciudadanía chilena, la cual en cumplimiento a centenaria tradición democrática y patriótica en defensa de los altos intereses de la Patria, he permitido con su oportuna información controlar 
y destruir estos importantes núcleos extremistas y tener actualizado el cuadro de los extremistas y extranjeros subversivos residentes, para limpiar nuestra patria de elementos indeseables que nada tienen que ver con nuestra tierra y origen común" (Junta Militar de Gobierno, 1973, p. 1).

Nuevamente, una palabra de profundo agradecimiento a supuestos delatores fue deslindada en el Bando $N^{\circ} 35$ del 18 de Septiembre de 1973 por parte de las nuevas autoridades:

"La Junta Militar manifiesta su profundo reconocimiento a la ciudadanía por el gran espíritu de responsabilidad demostrado al denunciar a los extremistas que en forma suicida estuvieron operando en algunos sectores de la capital" (Junta Militar de Gobierno, 1973, p. 1).

En dichos Bandos, se puso a disposición de la población una imagen positiva del delator, puesto que quien asumía dicho papel pasaba a ser conceptualizado por las nuevas autoridades como parte de un grupo superior de la población: la "ciudadanía consciente", poseedores de una "patriótica actitud" y de un "gran espíritu de responsabilidad". En la Sesión Secreta de la Junta Militar de Gobierno del 17 de Septiembre de 1973, se llegó al acuerdo de generar una plataforma de sistematización de los esfuerzos denunciadores de la población:

“3.- Se acuerda crear en la Comandancia de Guarnición de Santiago una oficina de "Investigación de denuncias", que cuente con su respectiva Carta de Situación a fin de poder controlar y coordinar adecuadamente esta actividad y evitar superposiciones" (Junta de Gobierno, 1973, p. 1) ${ }^{25}$.

Algunas semanas después, la Junta Militar de Gobierno instruyó a sus funcionarios a actualizar un Bando que tenía como finalidad incentivar económicamente la delación entre la población:

"12.- Se acuerda reactualizar el Bando que ofrece recompensas a quien entregue antecedentes sobre activistas buscados. Se instruye al señor Ministro del Interior al respecto" (Junta de Gobierno, 1973, p. 2) ${ }^{26}$.

¿En el caso específico del Trabajo Docente cómo operó este fenómeno de la delación? ¿Fueron acaso los Establecimientos Educacionales escenarios de delación entre sus integrantes? ¿Profesoras y profesores participaron de este fenómeno? Estas preguntas ya han sido respondidas positivamente por

\footnotetext{
${ }^{25}$ JUNTA DE GOBIERNO. Actas Junta de Gobierno. Santiago, Acta N ${ }^{\circ}$ 4, Sesión Secreta 17 Septiembre 1973. Página 1.

${ }^{26}$ JUNTA DE GOBIERNO. Actas Junta de Gobierno. Santiago, Acta N²4, Sesión Secreta 23 Octubre 1973. Página 2.
} 
otras personas. El Periodista Mauricio Weibel Barahona ha venido poniendo a disposición de la opinión pública chilena una serie de fuentes ${ }^{27}$ y reportajes ${ }^{28}$ que tratan sobre la existencia de una compleja red de espionaje y delación al interior de Escuelas y Liceos, la que tenía como gran objetivo identificar a opositores políticos de la Dictadura Militar, contando con el decidido apoyo de diferentes actores de las comunidades educacionales en el papel de delatores. Jaime Retamal Salazar $(2013)^{29}$, que recoge en su trabajo algunas fuentes publicadas por Mauricio Weibel Barahona, propone la siguiente mirada general sobre esta situación:

\begin{abstract}
"Lo que ha revelado Weibel no se trata simplemente de aquello que ya todos conocemos y es prácticamente parte de la nueva conciencia histórica de toda una generación de jóvenes, que la dictadura de Guzmán y Pinochet transformó al sistema educativo en uno de corte neoliberal condenando a miles de familias al marasmo de la mala educación; no, se trata más bien de algo nuevo e inquietante: se trata, revela Weibel de la dictadura adentro de las escuelas espiando a estudiantes y a profesores, se trata de más de 30 mil archivos que van desde el año 1982 al año 1988, se trata de apoderados o de docentes que delatan a otros chilenos en sendas cartas enviadas al mismo Pinochet, se trata del intento de formar la conciencia de miles de jóvenes en los contenidos afines al régimen, se trata de que el Ministerio de Educación tenía una Oficina de Seguridad que se comunicaba directa y diariamente con la Central Nacional de Inteligencia (CNI) a través de memorándums "informativos", se trata al fin de una coordinación inteligente, racional, sistemática y metódica sobre la base del mal radical que sustentó todo el quehacer vital de la dictadura -ahora, eso sí- dentro de las escuelas, dentro de las aulas y lo que es más inquietante dentro de las conciencias de miles de jóvenes" (Retamal, 2013, p. 58-59).
\end{abstract}

27 Estas fuentes corresponden a documentos de corte político/administrativo, propios de la comunicación entre diferentes actores de la Dictadura Militar, eso sí, con fines de inteligencia y represión política. Se trataría entonces, de miles de documentos de diferentes reparticiones públicas, con especial énfasis del Ministerio de Educación Pública, fechados mayoritariamente entre los años 1982-1989, mediante los cuales es posible identificar una serie de articulaciones represivas, pulcramente elaboradas y desarrolladas por parte de funcionarios públicos. En dichas fuentes, el accionar del aparato represivo, en este caso la Central Nacional de Informaciones (CNI), aparece de manera constante y empoderada, entregando y solicitando variadas informaciones, con el objetivo de implementar una política represiva efectiva, tanto al interior del Estado y de la Sociedad Civil. El acceso a estas fuentes fue posible gracias a la abierta y gentil disposición de los mismos por parte del Centro de Documentación del Museo de la Memoria y los Derechos Humanos (CEDOC; http://www. cedocmuseodelamemoria.cl/).

${ }_{28}$ Ver los siguientes artículos publicados en el semanario The Clinic: "Así nació la educación de Pinochet” (27/06/2013); “ ‘Operaciones Secretas’: El manual inédito de la DINA” (11/09/2013); “El documento secreto de la DINA para 'neutralizar' opositores en el mundo" (05/05/2015); "Gonzalo Vial: el gran espía de Pinochet y la CNI" (02/06/2015); "El pacto de silencio del abogado Alfredo Prieto" (05.08.2015). Ver: http://www.theclinic.cl/

${ }^{29}$ Retamal, J. Nos siguen pegando abajo. Jaime Guzmán, dictadura, concertación y alianza: 40 años de educación de mercado. Santiago: Ceibo Ediciones, 2013, 87 p. 
Efectivamente, al interior del Ministerio de Educación Pública operó una Oficina de Seguridad, al parecer, encargada de administrar las diferentes situaciones vinculadas a las tareas de vigilancia y persecución política dirigida a personas ubicadas en los Establecimientos Educacionales de Educación Básica, Media y Superior, como así también, ubicadas en los espacios de administración del sistema educacional a nivel nacional. Lo que muestran las fuentes consultadas es la existencia de una amplia red de comunicación entre el aparato de represión de la Dictadura Militar y diversas autoridades ubicadas en la administración pública. En el caso específico del Ministerio de Educación Pública, dicha red de comunicación contaba con la ayuda de la llamada Oficina de Seguridad para las tareas de coordinación y sistematización. De esta forma, la comunicación entre el Ministerio de Educación Pública y el aparato de represión era amplia y tenía una naturaleza institucionalizada, tal como quedó registrado en el Documento Secreto $\mathrm{N}^{\circ} 524$ del 21 de Noviembre de 1986, donde el Ministro de Educación Pública, el abogado Sergio Gaete Rojas, le comunicó al Director Subrogante de la CNI, Brigadier General Hugo Iván Salas Wenzel, la conveniencia de mantener el tipo de comunicación tradicionalmente establecido entre ambas dependencias hasta dicha fecha:

\begin{abstract}
"Cúmpleme manifestar a US. que se ha tomado debido conocimiento del oficio de la referencia y en consideración a la actual estructura y funciones de las dependencias de este Ministerio, no existe por ahora necesidad de establecer Canales independientes de Coordinación con esa Central. De consiguiente se mantendrá mientras subsistan las actuales condiciones, solo el canal jerárquico normal para los aspectos de Seguridad y enlace con esa Institución" (Ministerio de Educación Pública, 1986, p. 1).
\end{abstract}

En esta amplia e institucionalizada comunicación entre el Ministerio de Educación Pública y el aparato de represión, la Oficina de Seguridad cumplía la tarea de investigar los antecedentes políticos de personas que, por alguna razón, eran solicitados por las autoridades educacionales. En el Documento Reservado $N^{\circ} 720$, del 22 de Septiembre de 1982, el Jefe de la Oficina de Seguridad del Ministerio de Educación Pública, abogado Jorge Guerra Larraín, le entregó al Ministro de Educación Pública, Profesor Álvaro Arriagada Norambuena, los resultados de una de estas investigaciones:

"En cumplimiento de lo ordenado por US., referente a investigar los antecedentes que afectan a la Sra. CECILIA SOTO SCHIFFERLI, me permito informar a US., que verificados y analizados por esta Oficina, no habría inconveniente para acceder a lo solicitado por la señora Soto" (Ministerio de Educación Pública, 1982, p. 1).

La Oficina de Seguridad del Ministerio de Educación Pública aparace realizando otras tareas de investigación más amplias. Mediante Memorándum 
sin autoria y datado el 07 de Enero de 1983, se alerta sobre la realización de actividades contrarias a la Dictadura Militar en el Establecimiento Educacional Particular Subvencionado Colegio Regina Pacis, ubicado en la Comuna de Núñoa de la ciudad de Santiago y perteneciente a la Congregación de los Sagrados Corazones de Jesús y María. El motivo de la alerta apuntó a la orientación política de algunos integrantes de la comunidad educacional:

\begin{abstract}
“c. Su Directora, la religiosa ANA CECILIA MUÑOZ LOPEZ, manifiesta una evidente posición contraria al Gobierno traducida, en forma especial, en el hecho de acreditar y avalar acciones y comentarios desfavorables para las Fuerzas Armadas o el Gobierno. d. Esa abierta desafección le lleva, incluso, a ignorar disposiciones del Ministerio de Educación, relativas a la obligatoriedad de izar el pabellón patrio, bajo los acordes del himno nacional, al iniciarse cada semana lectiva del año escolar" (S/I, 1983, p. 1).
\end{abstract}

La supuesta posición política de oposición de la Directora Ana Cecilia Muñoz López, habría favorecido la organización de un grupo de docentes “disidentes", compuesto por Gonzalo Edmundo Ramos Schwarbenger, Hernán Alfredo Soto Paredes y Pedro Eleuterio Soto Paredes, quienes realizarían las siguientes actividades:

"e. Su actitud ha conducido a la formación de un grupo de profesores disidentes, cuyas acciones son apoyadas por la directora mencionada y a los cuales se les permite reunirse, semanalmente, en dependencias de la Parroquia Santa Bernardita, conectada interiormente con el establecimiento educacional. Dichas reuniones se realizan bajo el calificativo de "encuentros de tipo pastoral"' (S/I, 1983, p. 1).

Un aspecto sorprendente, es que la información que presenta dicho Memorándum sobre este grupo de docentes "disidentes" es bastante acabada, puesto que incluye el nombre completo, número de cédula de identidad, nacionalidad, fecha de nacimiento, nombre de los hijos, profesión y cargo de estas personas. Esto sugiere que, posiblemente, el Memorándum fue elaborado por personas que tenían un privilegiado acceso a bases de datos que contaban con una organizada información personal de la población. Con posterioridad, la Oficina de Seguridad del Ministerio de Educación Pública aparece vinculada al caso de la Escuela Regina Pacis. El 25 de Mayo de 1983, mediante el Documento Reservado $N^{\circ}$ 29, el Jefe Superior de Seguridad del Ministerio de Educación Pública, Coronel de Ejército Atiliano Jara Salgado, informaba al Subsecretario de Educación Pública sobre la situación de la Escuela Regina Pacis. En el informe del Coronel de Ejército Atiliano Jara Salgado se deja entrever la realización de un importante proceso de revisión de varios aspectos de dicho Establecimiento Educacional, identificándose la existencia 
de un estado de normalidad mezclado con algunas "anomalías subsanables". En dicho proceso de revisión, los problemas de orden político identificados con anterioridad aparecen como una tarea que abiertamente fue entregada al seguimiento del aparato de represión:

"Con respecto al comportamiento del Director y profesores del establecimiento, se observará un control periódico a través de la C.N.I., de tal forma que al comprobar reincidencias por parte de algunos de los docentes, se estudiaría la forma de aplicar las sanciones al colegio, en relación a su función cooperadora del Estado, recomendándole cambiar de proceder o efectuar cambio de docentes" (Ministerio de Educación Pública, 1983, p. 1).

El proceso de intercambio de información que apuntaba a generar condiciones para vigilar y perseguir a docentes, y demás integrantes de las comunidades educacionales, asumía diferentes direcciones y todo indica que se situaba con un estatus de alta importancia dentro de las tareas cotidianas de diferentes perfiles de actores. El Ministro de Educación Pública, abogado Sergio Gaete Rojas, aparece en las fuentes consultadas como un activo interlocutor de la CNI, enviando a dicho organismo represor informaciones sobre variados actores y eventos. En el Documento Reservado $\mathrm{N}^{\circ} 174$ del 29 de Abril de 1986, dicho funcionario aparece remitiendo al Director de la CNI datos de Establecimientos Educacionales y de estudiantes que potencialmente serían de interés para dicho aparato represivo, solicitando además la realización de un procedimiento de chequeo de los antecedentes de dichos estudiantes:

\begin{abstract}
"Cumplo con remitir a US. carta firmada por el Secretario Nacional de Juventudes Nacionalistas de Chile, en la cual adjunta documentos pertenecientes a establecimientos educacionales de la Región Metropolitana. Por lo antes expuesto, solicito a US. verificar los antecedentes de éstos jóvenes y tomar las medidas que esa Central estime convenientes" (Ministerio de Educación Pública, 1986, p. 1).
\end{abstract}

A través del Documento Reservado $N^{\circ} 191$ del 19 de Mayo de 1986, el Ministro de Educación Pública Sergio Gaete Rojas, accionó al Director de la CNI para indagar sobre una supuesta negligencia cometida en una dependencia regional de dicho Ministerio:

\footnotetext{
"Me dirijo a US. para manifestarle que en este Gabinete se ha recibido información respecto de una probable negligencia de la Secretaria Ministerial de Educación de la VII ${ }^{\text {a }}$ Región, Sra. Dora Ulloa Rojas, en relación a actos contrarios a los principios de Gobierno que realizarían funcionarios de dicha dependencia. Por lo antes expuesto, mucho agradeceré a US. tenga a bien informarme de los antecedentes que puedan obrar en esa Central, en relación a la Secretaria Ministerial de Educación de la VII ${ }^{\text {. }}$ Región" (Ministerio de Educación Pública, 1986, p. 1).
} 
Nuevamente, el Ministro de Educación Pública Sergio Gaete Rojas accionó al Director de la CNI solicitándole información sobre algunos docentes a través del Documento Reservado № 519 del 29 de Octubre de 1986:

"Me permito hacer llegar a US., carta que me enviara un grupo de Padres y Apoderados de Viña del Mar, denunciando actitudes contrarias al Supremo Gobierno de los profesores RENE HERRERA PEREZ y su esposa FRESIA AZOLA DE HERRERA, afectando especialmente a los hijos quienes son alumnos de estos profesores. Por lo antes expuesto, ruego a US. si lo tiene a bien, me informe si corresponden los cargos formulados a los referidos profesores" (Ministerio de Educación Pública, 1986, p. 1).

Desde la CNI también se despachaban diferentes comunicaciones dirigidas al Ministerio de Educación Pública. El 01 de Julio de 1983 el Director de la CNI, Mayor General Humberto Gordon Rubio, le envió información a la Ministra de Educación Pública, abogada Mónica Madariaga Gutiérrez, sobre la "situación disidente en colegios particulares" mediante el Documento Reservado $\mathrm{N}^{\circ}$ 211327. El objetivo de dicha comunicación fue justamente el de dar a conocer a la autoridad educacional el desarrollo de actividades de orden político en Establecimientos Educacionales, específicamente, la participación de docentes en las protestas nacionales y el llamado de los mismos a los estudiantes a no asistir a clases en los días que estas manifestaciones y protestas se desarrollaron. Estas situaciones se habrían desarrollado en el Colegio Pedro de Valdivia, en el Colegio San Ignacio y en otros Establecimientos Educacionales Católicos de la capital. El foco de cuestionamiento fundamental apuntado por el Mayor General Humberto Gordon Rubio contra esta "situación disidente en colegios particulares" se dirigió hacía el impacto que dichas actitudes del profesorado podría tener en los estudiantes:

"Las situaciones planteadas revisten carácter de gravedad si se considera que las actuaciones y ejemplos de los docentes tienen gran influencia y trascendentales efectos en los educandos que, en los casos señalados son perniciosos y negativos" (Central Nacional de Informaciones, 1983, p. 1).

De esta forma, la potencial influencia del profesorado que sostenía posiciones y actuaciones críticas contra la Dictadura Militar sobre sus estudiantes era visualizada como un profundo peligro que era necesario ser enfrentado. Esta potencial influencia del profesorado podría desembocar en la formación de enemigos de la Dictadura Militar entre las filas del estudiantado chileno, situación imposible de ser asumida pasivamente por el aparato de represión: 


\begin{abstract}
“7. La posición adoptada por los colegios y la actitud asumida por sus equipos docentes constituyen una presión psicológica directa sobre los estudiantes, influyendo sobre toda una generación joven que cuestiona el quehacer de las autoridades y la inducen a adoptar una posición político-partidista que, dada la natural rebeldía de la juventud, puede desembocar en anarquismo y quebrantar los principios básicos del Sistema Nacional de Educación. 8. Todo lo anterior lleva a pensar en la necesidad urgente de revisar los actuales sistemas de control, de fondo y forma, sobre los colegios particulares con el propósito de evitar se produzca nuevamente un ausentismo masivo de profesores, por móviles políticos, y que estos colegios se transformen en agentes de doctrinas políticas y formadores de líderes ajenos a los principios nacionales" (Central Nacional de Informaciones, 1983, p. 2).
\end{abstract}

Otra comunicación dirigida por el Director de la CNI, Mayor General Humberto Gordon Rubio, a la Ministra de Educación Pública, Mónica Madariaga Gutiérrez, se encuentra en el Documento Reservado ํㅜ 211708 del 18 de Agosto de 1983. Lo interesante de dicha comunicación es que el objeto de seguimiento y análisis de la CNI correspondió a un actor diferenciado, específicamente la Corporación Educacional Alonso de Ercilla, encargada de administrar los Establecimientos Educacionales que mediante el proceso de Municipalización fueron transferidos a la Municipalidad de San Fernando de la VI ${ }^{\mathrm{a}}$ Región. El problema detectado por el aparato represor corresponde a la ocurrencia de una serie de irregularidades de orden financiero cometidas por dicha Corporación Educacional, que tendrían el efecto peligroso de posicionar al profesorado de dicha Comuna en contra de la Dictadura Militar:

“2. La mencionada Corporación Educacional efectúa descuentos mensuales por planilla a 16 profesores, para remitirlos a la Cooperativa de Viviendas "El Covigal Ltda.", Villa Los Maitenes de San Fernando. Existen antecedentes que ese dinero no es remitido a la Cooperativa de Viviendas, sino que es utilizado por la Corporación Educacional en otros rubros, perjudicando gravemente a los profesores. 3. En el profesorado de San Fernando existe un profundo malestar por esta situación, pues se sienten, una vez más, postergados profesional y económicamente, creando un clima de desconfianza hacia el Gobierno, proyectando una mala imagen a la opinión pública, derivado de errores administrativos del Departamento de Educación Municipal de la comuna y agudizado por el reciente fraude de 'CODELMA' a un vasto grupo de profesores” (Central Nacional de Informaciones, 1983, p. 2).

En dicha Fuente, la CNI muestra su poderosa capacidad de vigilancia e inspección sobre diferentes situaciones y actores que tenían algún nivel de vinculación con el sistema educacional. Además de dicha capacidad de vigilancia e inspección, resulta llamativa la intervención directa que el Director de la CNI realizó sobre materias de la Política Pública Educacional, 
transmitiéndole a la Ministra de Educación, de manera frontal y sin resquemor alguno, su mirada sobre cómo se debería llevar adelante la implementación de algunas tareas de una manera efectivamente conveniente para el Régimen:

"4. Considerando los antecedentes negativos y las numerosas irregularidades cometidas por la Corporación Educacional "Alonso de Ercilla", en tan sólo cuatro meses de administración, parece necesario adoptar medidas precisas con el objeto de impedir que organizaciones con intereses personales de lucro o políticos se hagan cargo de Corporaciones Educacionales, desvirtuando los principios del Supremo Gobierno en Educación, utilizándolas como un medio para obtener dividendos económicos o políticos" (Central Nacional de Informaciones, 1983, p. 2-3).

En todo este complejo tránsito de informaciones, carpetas con los datos de profesoras y profesores ocuparon los escritorios de diversos actores vinculados a la Dictadura Militar dedicados a las tareas de vigilancia y persecución política. Actividades docentes, postulaciones a puestos de trabajo, actos cívicos, tareas gremiales, entre muchas otras, fueron objeto de atentos escrutinios por parte de diferentes censores. Los efectos de estos ejercicios de escrutinio de antecedentes de profesoras y profesores, con interés de vigilancia y persecución política, podían tener efectos muy concretos en la vida de dichas personas. Esto es posible de ser identificado en la comunicación enviada por el Coordinador del Departamento de Inspección y Control del Ministerio de Educación Pública, Víctor González Olivencia, al Subsecretario del mismo Ministerio, mediante Documento Reservado $N^{\circ} 4$ del 15 de Febrero de 1983. En dicha comunicación es posible identificar un intercambio de informaciones al más alto nivel entre autoridades públicas, proceso que tuvo como consecuencia final la exoneración del Profesor Roberto Huenchuleo Hircaleo de su puesto de trabajo por razones de índole política:

"1. En atención a la Minuta Res. Mencionada en antecedentes, informo al señor Subsecretario de Educación que el señor ROBERTO HUENCHULEO HUIRCALEO, ex-Profesor de la Escuela G. $N^{\circ} 815$, de Cañete, fue removido de su cargo, por aplicación de las disposiciones del Art. $5^{\circ}$ del D.L. $\mathrm{N}^{\circ} 2345$ de 1978, según Decreto del Ministerio del Interior $\mathrm{N}^{\circ} 326$, de 29.03 .82 y notificado por la Secretaría Ministerial de la VIIIa. Región. 2. Los antecedentes que sirvieron de base para su exoneración del servicio llegaron a través de la Subsecretaría del Ministerio del Interior y fueron proporcionados por el señor Intendente de la VIIIa. Región del Bío-Bío, según fojas 8 y 9., y se refieren a incumplimiento de normas educacionales, oposición crítica al régimen actual de gobierno y desarrollo de actividades de proselitismo político" (Ministerio de Educación Pública, 1983, p. 1). 
El 26 de Abril de 1983 el Director de Inteligencia de la Defensa Nacional, Brigadier Iván de la Fuente Sáez, envío al Subsecretario de Educación, mediante Documento Reservado $\mathrm{N}^{\circ}$ 2450/22, la siguiente alerta sobre una "Prueba de Diagnóstico" elaborada y aplicada en el Colegio Sagrados Corazones:

\begin{abstract}
"Se remite a US., una "Prueba de Diagnóstico" realizada al 3er. Año Medio del Colegio Sagrados Corazones, este documento fue entregado a esta Dirección por un apoderado de dicho Colegio. Dado el evidente carácter político y tendencioso de dicho documento, se estima conveniente efectuar una investigación al respecto" (Ministerio de Defensa Nacional, 1983, p. 1).
\end{abstract}

El 30 de Mayo de 1983, a través del Documento Reservado $N^{\circ} 75$, el Gobernador de la Provincia de Limarí, Teniente Coronel de Carabineros Sergio Brieba Hinrichsen, puso al tanto al Intendente de la IV Región de Coquimbo de los resultados de una investigación solicitada por el Ministerio del Interior en torno a datos de dos docentes que se encontraban postulando a unos puestos de trabajo. En dicho informe, los primeros resultados indicaban la siguiente situación:

"1.2. Averiguamos los antecedentes respectivos, el Sr. HECTOR S. BARRERA
RAMIREZ, registraba militancia en el ex-partido comunista, posteriormente se
informó al Sr. Alcalde de la Comuna de Punitaqui, mediante RES. N ${ }^{\circ}$ C-10, de
fecha 27.ENE.82, de esta Gobernación Provincial, que solamente se encontraba
habilitado el Sr. García Galleguillos" (Gobernación Provincia Limarí, 1983, p. 1).

No obstante lo anterior, en revisiones posteriores del Teniente Coronel de Carabineros Sergio Brieba Hinrichsen, se fue avanzando a una mirada diferente sobre la situación del Profesor Héctor Barrera Ramírez:

\begin{abstract}
“4. Conforme a lo informado por la Subprefectura de Carabineros de Limarí, con la reactualización de los antecedentes personales y políticos de las personas fichadas con posterioridad al año 1973, y, en conformidad al Oficio Reservado $\mathrm{N}^{\circ} 7082$, de fecha 8 de Noviembre de 1982, de la Dirección de Informaciones y Comunicaciones, quedaría sin antecedentes políticos por no haber participado en hechos contrarios a la política del Supremo Gobierno, y encontrarse integrado a la comunidad" (Gobernación Provincia Limarí, 1983, p. 2).
\end{abstract}

La modificación de la actuación pública del Profesor Héctor Barrera Ramírez, que habría pasado de una condición de militante de un Partido Político a otra de no tener actuación política opositora a la Dictadura Militar, terminó convenciendo a los censores de que dicho docente ahora se encontraría "integrado a la comunidad". Esta transformación aparente, consiguió alcanzar la aprobación de los censores, lo que se materializó finalmente en una autorización para que posibles empleadores públicos contrataran al Profesor Héctor Barrera Ramírez, en caso de existir la posibilidad: 
"5. De acuerdo a lo expuesto en el $\mathrm{N}^{\circ} 4$ de este informe, se ofició a las Ilustres Municipalidades de Combarbalá y Punitaqui, que el Sr. HECTOR SEGUNDO BARRAZA RAMIREZ, está habilitado para desempeñar labores de docencia, motivo por el cual, puede ser contratado siempre que exista disponibilidad de cargos vacantes" (Gobernación Provincia Limarí, 1983, p. 2).

El 13 de Junio de 1984, la Jefa del Gabinete de la Subsecretaría de Educación, Profesora de Estado Pamela Guerrero Guerrero, envió al Director de Orden y Seguridad el Documento Reservado $N^{\circ}$ 02/128 con el objetivo de acusar recibo de una comunicación anterior dirigida por este con respecto del procesamiento judicial iniciado contra el Profesor Carlos Gómez Cabello:

"Me permito acusar recibo de su Reservado $\mathrm{N}^{\circ} 204$ de fecha 11 de Junio en curso, por el cual informa sobre que se ha puesto a disposición del Ministerio del Interior por infracción a la Ley de Seguridad del Estado, al profesor Carlos R. Gómez Cabello. Al respecto comunico a Ud. que se ha dado las instrucciones correspondientes de acuerdo al documento en referencia" (Ministerio de Educación Pública, 1984, p. 1).

El 02 de Mayo de 1985 el Subsecretario de Educación, Profesor René Salamé Martín, solicitó al Subdirector de la CNI antecedentes sobre el Profesor Marcelo Vicente Retamal Galaz, que se encontraba realizando gestiones para lograr reincorporarse a su puesto de trabajo en el mismo Ministerio de Educación Pública:

"1. Por antecedentes que obran en poder de esta Subsecretaría no existirían datos concretos que avalen la remoción del Profesor MARCELO VICENTE RETAMAL GALAZ. 2. En consideración a que el Prof. Retamal está solicitando su reincorporación en un Centro de Diagnóstico del Ministerio de Educación Pública, me permito solicitar a US., se estudie las razones que se tuvieron presente para la aplicación de la medida señalada" (Ministerio de Educación Pública, 1985, p. 1).

El 11 de Abril de 1986, el Ministro de Educación Pública, Sergio Gaete Rojas, envió el Documento Reservado Nº1 148 al Jefe de Zona de Estado de Emergencia de la Región Metropolitana y Provincia de San Antonio, donde le agradeció el envío de una importante información:

"He tomado conocimiento de su Of. Reservado indicado en antecedente, mediante el cual me informa que en el Colegio Don Bosco, por orden del Director del establecimiento, al entonar el Himno Patrio, se omitió la última estrofa. Al respecto, cumplo con manifestarle que se envió supervisión al citado plantel, pero por ser éste un Colegio particular pagado, este Ministerio no está facultado para tomar más medidas" (Ministerio De Educación Pública, 1986, p. 1). 
Todas estas fuentes citadas tienen en común la marca de la acción de vigilancia y persecución política direccionada al profesorado por parte de diferentes actores de la Dictadura Militar, además, permitiendo inferir consecuencias muy concretas y específicas en la vida de estas personas. Esta acción de vigilancia y persecución política dio paso a la articulación de técnicas y procedimientos de organización y consulta de datos de profesoras y profesores a lo largo de Chile. Es posible aventurar la existencia de un fondo documental de informaciones sobre profesoras y profesores, como así también de otros actores del sistema educacional, al modo de un amplio catastro de nombres, actividades y sensibilidades políticas, todas inscritas en formularios y carpetas, metódica y constantemente completadas y consultadas. Solamente con la existencia de dicho fondo documental serían viables las mencionadas acciones de vigilancia y persecución política ya visualizadas a través de estas fuentes. De hecho, sólo con la existencia de ese posible fondo documental los aparatos de represión pudieron realizar su institucional y conocida tarea de chequear cuidadosamente las informaciones personales y políticas de cualquier persona que trabajaba o pretendía trabajar en cualquier organismo o empresa vinculada al Estado. Dos fuentes permiten acceder a parte de dicha situación.

El 19 de Enero de 1976, el Secretario de Coordinación Subrogante de la Dirección de Inteligencia Nacional (DINA), envió el Documento Secreto $\mathrm{N}^{\circ}$ 2412/155 al Ministro de Relaciones Exteriores, Vicealmirante Patricio Carvajal Prado, a través del que remitió a este último la Circular Reservada $\mathrm{N}^{\circ} 2$ del Ministerio del Interior emitida el 07 de Enero de 1976. En dicha Circular Reservada $\mathrm{N}^{\circ} 2$, que posiblemente fue enviada a autoridades de diferentes reparticiones del Estado, se estableció claramente la modalidad en que se organizaría la solicitud de informaciones sobre diferentes personas al interior de la administración estatal:

“a) De acuerdo a lo ordenado por S.E. el Presidente de la República, sólo DINA entregará antecedentes de personas a los Ministerios, Reparticiones Públicas e Industrias del Área Estratégica, por intermedio de su Secretaria de Coordinación. Las peticiones de antecedentes deberán hacerse por medio de las respectivas Oficinas de Seguridad” (Ministerio del Interior, 1976, p. 1).

Años después, el 25 de Julio de 1983, el Subsecretario de Educación Pública, Capitán de Fragata Juan Enrique Fröemel Andrade, envió el Oficio de Circulación Reservada N 98 a los "Señores Jefes de Servicio" con el objetivo de enviarles la información que el Ministro del Interior hizo llegar a todos los Ministros de Estado (a través de la Circular Reservada $N^{\circ} 43$ del 06/07/1983) sobre normas de seguridad a considerar con respecto a los funcionarios públicos. La primera información destacada en esta comunicación se orientaba a valorar el papel insustituible y necesario que jugaba el aparato represor al momento de contratar nuevo personal: 
"1. Por Circular individualizada en primer lugar del antecedente, se comunicó a los Sres. Ministros de Estado, con encargo de disponerlo a todos los servicios dependientes, el mandato Presidencial de que ningún funcionario público fuera contratado sin que se contara con un informe de confiabilidad emitido por la Central Nacional de Informaciones" (Ministerio de Educación Pública, 1983, p. 1).

La revisión de los antecedentes de funcionarios públicos no se limitaba solamente al momento de ingreso a trabajar en la administración o empresas públicas, puesto que los informes de confiabalidad elaborados por la CNI tendrían validez para ser utilizados en instancias de "Contratar, recontratar o exonerar...”. (Ministerio de Educación Pública, 1983, p. 1). El hecho de que estas normas de seguridad fuesen reiteradas, potencialmente respondía a que las mismas no venían siendo seguidas de manera adecuada, por lo mismo, estas adquirieron desde aquel momento un esctricto carácter de obligatoriedad, considerando las siguientes instrucciones:

“a) Toda contratación de personal deberá contar con el respectivo informe previo de confiabilidad, emitido por la Central Nacional de Informaciones. b) Deberá disponerse una revisión de los antecedentes del personal dependiente, para lo cual se considerarán los informes emitidos, a la fecha, por la Central Nacional de Informaciones y, en caso de ser necesario, se requerirá de ella nuevos informes. Las reparticiones regionales o provinciales deberán dirigirse a las unidades locales de la Central Nacional de Informaciones, para tales efectos. c) Por otra parte, se deberá ejerecer una discreta vigilancia sobre las eventuales actividades y acciones contrarias al Gobierno que se detecten, desarrolladas por funcionarios de las reparticiones y/ o Empresas dependientes del Estado" (Ministerio de Educación Pública, 1983, p. 2).

Tal como ya fue señalado, todo este amplio e institucionalizado esquema de intercambio de información entre diferentes actores de la Dictadura Militar, con destaque de los agentes del aparato de represión, para realizar de manera efectiva las tareas de vigilancia y persecución política hacía profesoras y profesores, sólo fue viable mediante la elaboración de un fondo documental con amplios antecedentes de estas personas. El funcionamiento efectivo de todo este sistema de vigilancia y persecución política difícilmente hubiese alcanzado un radio de acción amplio y complejo si se hubiese limitado al aporte exclusivo de los agentes del aparato de represión y de las jefaturas político/administrativas del Estado. Fue necesario ir mucho más allá de los esperables servicios de dichos funcionarios y captar apoyos entre la Sociedad Civil, multiplicando así la capacidad vigilante/persecutoria de la Dictadura Militar. En este plano, la delación se constituyó en un combustible que potenció y aceitó toda la maquinaria represiva, dinamizando redes de espionaje y acusación en los diferentes espacios de la sociedad, creando nuevas e inusitadas 
solidaridades represivas dispuestas a transmitir cualquier detalle ínfimo donde se asomaran posturas críticas hacia el Régimen. En las fuentes aquí revisadas la delación aparece de manera insistente y sorprendente, envolviendo a sujetos variados, desde aquellos escondidos bajo el anonimato, pasando por funcionarios públicos de diferentes jerarquías, hasta llegar a personajes de destaque de la Dictadura Militar. Siguiendo este último punto, la mismísima María Lucía Hiriart Rodríguez, esposa del General Augusto Pinochet Ugarte, se mostraba atenta y activa en estas tareas de acusación. El 04 de Octubre de 1988, mediante Oficio Reservado $N^{\circ}$ 185/2128, María Lucía Hiriart Rodríguez alertó al Ministro de Educación Pública, Juan Antonio Guzmán Molinari, sobre la inconveniencia de la reciente contratación de un funcionario público, debido a los antecedentes manejados sobre sus orientaciones políticas:

"Pongo en su conocimiento que recientemente he sido informada que el Señor
Humberto Vera Pérez, actual Secretario Regional Ministerial de la XIIa. Región
es una persona de afiliación política socialista y totalmente contrario a los
postulados del Supremo Gobierno. Derivado de la gravedad de este hecho, por
tratarse de un funcionario que ocupa un cargo representativo, agradeceré a Ud.
Administrar las medidas que estime pertinentes" (Gabinete Primera Dama de
la Nación, 1988, p. 1).

La delación envolvió a diferentes actores y asumió direcciones inesperadas. E1 20 de Enero de 1986, el Ministro de Educación Pública, Sergio Gaete Rojas, transmitió al Secretario Ministerial Regional de Educación, Benigno Saralegui, el contenido de una delación recibida por parte de padres y apoderados de un Establecimiento Educacional a través del Documento Reservado $\mathrm{N}^{\circ} 03$ :

"1. Por conducto regular se ha hecho llegar a este Ministerio diversas denuncias de padres y apoderados del Instituto Salesiano de Valdivia relacionadas con irregularidades y abusos cometidos en el plantel. Versan ellas sobre arbitrariedades en la evaluación escolar con alumnos miembros de familias vinculadas a instituciones armadas $\mathrm{u}$ oficiales, $\mathrm{y}$ cobros injustificados, supuestamente ilegales, que se exigirían en el mismo" (Ministerio de Educación Pública, 1986, p. 1).

Nuevamente por intermedio del Ministro de Educación Pública, Sergio Gaete Rojas, es posible acceder a una delación. Dicho Ministro envió el día 20 de Septiembre de 1986 una carta (Documento $N^{\circ} 01$ 472) a Domingo Cárdenas Marín, con la finalidad de agradecerle el envío de determinadas informaciones:

"Me es grato acusar recibo de su atenta carta, en la cual manifiesta su preocupación por la circulación y distribución en los establecimientos educacionales, de panfletos ofensivos al Gobierno, los que estarían siendo repartidos en provincias y especialmente en Puerto Montt. Al respecto y, junto 
con agradecerle esta información, le manifiesto que he puesto en conocimiento esta denuncia al señor Secretario Ministerial de Educación y al Sr. Intendente de la X. Región, dado a que comparto sus apreciaciones" (Ministerio de Educación Pública, 1986, p. 1).

El 15 de Julio de 1986, el Ministro de Educación Pública, Sergio Gaete Rojas, envió el Documento Reservado N³09 al Secretario Regional Ministerial de la VIII ${ }^{\text {a }}$ Región, Luis Alvear López, con el objetivo de comunicarle el recibo de determinadas acusaciones de interés:

"En los últimos meses se han dirigido a este Gabinete denuncias de padres y
apoderados relacionadas con hechos o actividades políticas del todo ajenas a la
labor formativa, realizadas en algunos planteles educativos. Algunas de ellas
afectan al Colegio Salesiano de Concepción. A fin de evitar en lo posible estas
anomalías denunciadas por la comunidad, es necesario que esa repartición a la luz
de las facultades que le competen, procure las iniciativas adecuadas tendientes
a garantizar a los padres de familia de los establecimientos subvencionados,
sus derechos en torno al proceso educacional del cual participan sus hijos"
(Ministerio de Educación Pública, 1986, p. 1).

De estas prácticas de delación también participaron profesoras y profesores, denunciando a colegas de trabajo o a otros integrantes de la comunidad educacional. Ejemplos de esto los encontramos en sendas cartas escritas a las nuevas autoridades por parte de docentes pocos días después del Golpe de Estado del 11 de Septiembre de 1973. El 13 de Septiembre de aquel año, el Profesor Hernán Briones Toledo, Consejero Nacional del Sindicato Único de Trabajadores de la Educación (SUTE) y Asesor Pedagógico de la Escuela de Infantería de San Bernardo, envió una carta al Ministro de Educación Pública, José Navarro Tobar, expresándole su adhesión al ideario de las nuevas autoridades y también su disposición a colaborar con las mismas desde sus posibilidades:

\begin{abstract}
"Señor Ministro: En las contingencias que vive nuestra Patria, me dirijo a Ud. para significarle mi más absoluta adhesión a los postulados que inspira la acción de la Junta Militar que ha tomado sobre sus hombros la labor de la reconstrucción nacional. (...). Así, deseo aprovechar esta ocasión, señor Ministro, para ofrecer a Ud. mi incondicional colaboración en el seno de mi actividad profesional para cualquiera determinación de ese Ministerio, con el objeto de depurar la acción pedagógica sé muy bien cuán deteriorada se encuentra" 30 .
\end{abstract}

${ }^{30}$ Briones, H. Carta a Ministro de Educación Pública, Santiago, 13 Septiembre 1973 apud Retamal, J. Nos siguen pegando abajo. Jaime Guzmán, dictadura, concertación y alianza: 40 años de educación de mercado. Santiago: Ceibo Ediciones, 2013, 87 p. 
Para el Profesor Hernán Briones Toledo, una manera adecuada para alcanzar la "depuración” del Trabajo Docente sería el emprendimiento de una serie de ejercicios escrutadores:

\begin{abstract}
"A modo de información, me permito insinuar al señor Ministro alguno de los puntos en que, según mi criterio y conocimientos, se imponen drásticas investigaciones y severas medidas: - Sumarios por acción proselitista y no pedagógica de algunos profesores; - Investigación sobre programas que no cumplen por criterios políticos de profesores marxistas; - Irregularidades en descuentos y pago de días de no trabajados o pago doble a algunos profesores en comisión de servicio; - Robos o inventarios adulterados o falseados; - Estudio de modificación de programas excesivamente condescendientes con materias atingentes al marxismo; - prohibición de textos de ciertos autores claramente pro-marxistas; - excesivas permisiones a los alumnos en el aspecto disciplinario. - falta de un reglamento de liceo moderno pero de rigurosa aplicación; - severa auditoria del SUTE; - politización excesiva de la acción del SUTE, etc." ${ }^{31}$.
\end{abstract}

El abanico a asuntos sugeridos por el Profesor Hernán Briones Toledo a ser indagados era amplio, incluyó desde problemas de orden administrativo/ judicial hasta aquellos de orden más político/ideológico. Con respecto a estos últimos, la politización y la adscripción al Marxismo fueron visualizadas como opciones inaceptables para el profesorado según la perspectiva de este docente, razón que, por sí misma, justificaba el llamado a emprender un severo proceso de investigación. Finalmente, después de poner en juego todos sus argumentos, disponibilidades y focos de ataque, el Profesor Hernán Briones Toledo pasó a despedirse del Ministro de Educación Pública y a realizar una meta-lectura de sí mismo y su carta, inscribiéndose dentro del grupo de aquellos docentes "conscientes":

"Sin otro particular por el momento, creyendo cumplir con un deber de mi cargo de Consejero y profesor consciente, aprovecho esta oportunidad para desear éxito al señor Ministro a la vez que le hago presente que me consideraré afortunado de contribuir con mi colaboración en sus afanes patrióticos" ${ }^{2}$.

El 10 de Octubre de 1973, la Directora de la Escuela Normal de La Reina, Olga Monserrat Rivas, dirigió una carta al Subdelegado Interino de La Reina con el objetivo de delatar al Profesor de Educación Cívica, Franklin Troncoso Bachler, con respecto a su comportamiento y opiniones esgrimidas durante su actividad docente. Basándose en antecedentes entregados por un grupo de estudiantes, la Directora Olga Monserrat Rivas acusaba al Profesor Franklin

31 Briones, H. Carta a Ministro de Educación Pública, Santiago, 13 Septiembre 1973 apud Retamal, J. Nos siguen pegando abajo. Jaime Guzmán, dictadura, concertación y alianza: 40 años de educación de mercado. Santiago: Ceibo Ediciones, 2013, 87 p.

32 Ídem. 
Troncoso Bachler de "(...) expresar a los alumnos del curso en referencia, una ola de rumores destinados a crear una falsa imagen de las Fuerzas Armadas y del Cuerpo de Carabineros de Chile"33. Los “rumores" que el Profesor de Educación Cívica habría ventilado es sus aulas serían los siguientes:

"Entre otras cosas manifestó que él en su calidad de General de Carabineros Retirado, personalmente, había tenido la oportunidad de presenciar en un Cuartel de Carabineros, ubicado en calle Chiloé, el trato implacable para los prisioneros de la U.P., donde el personal uniformado los pisoteaba en el suelo fracturando sus miembros, aparte de otras atrocidades. Ante tales aseveraciones, alumnas de tendencia de izquierda estallaron en llanto, mientras otros de ideas democráticas se retiraron de la sala de clases rechazando de plano tales juicios; estimo que con estas actitudes, el citado profesor solo consigue alarmar al estudiantado, estimulándolo al odio y a las pasiones más negativas en contra del Supremo Gobierno"34.

En las palabras de la Directora Olga Monserrat Rivas es posible encontrar la fuerza de la negación a la posibilidad de veracidad del testimonio del Profesor Franklin Troncoso Bachler, además, es posible encontrar una fuerte crítica a los potenciales efectos que este perfil de testimonio podría desencadenar contra los intereses del "Supremo Gobierno". Como los intereses del "Supremo Gobierno" se encontrarían a salvo de cualquier intento de cuestionamiento o rumor, la Directora Olga Monserrat Rivas en su carta asumió un papel de delatora y jueza a la vez, justificando la asunción del mismo en base a una lectura personal del momento político que atravesaba Chile:

"En atención a que situaciones como estas, a mi juicio, no es posible tolerarlas, porque las estimo de suma gravedad, para el momento de transición que vive nuestro querido Chile, me siento en el deber de comunicarla a Ud., dada su calidad de Primera Autoridad de Gobierno de la Comuna, para los fines que estime procedentes" 35 .

Un tercer ejemplo se encuentra en la carta que la Profesora Normalista Lorenza Núñez Cabrera escribió a la Ministra de Educación Pública, Mónica Madariaga Gutiérrez, el 07 de Marzo de 1983. En dicha comunicación, la Profesora Normalista Lorenza Núñez Cabrera acusaba el hecho de haber sido despedida del Colegio Andacollo de la ciudad de Santiago, en Diciembre de 1982, junto a dos colegas más, por cuestiones de orden político, más específicamente por “(...) no estar en la línea pastoral del colegio, la cual es de abierta oposición al Gobierno presidido por el señor Augusto Pinochet". (Ministerio de Educación Pública, 1983, p. 3). Agregó que después de buscar

\footnotetext{
33 Ídem.

34 Ídem.

35 Ídem.
} 
infructuosamente una solución frente a autoridades de la Iglesia Católica, propietaria de dicho Establecimiento Educacional, optó por escribir directamente al General Augusto Pinochet Ugarte y a la misma Ministra de Educación Pública, cuestionando en todo momento la orientación, supuestamente política, que vendría asumiendo el trabajo pedagógico y pastoral en el Colegio Andacollo, identificando al Rector del mismo, el sacerdote estadounidense Gerald Richard Barmasse Linteo, como uno de los principales responsables de dicho fenómeno. Para finalizar, la Profesora Normalista Lorenza Núñez Cabrera justificó su carta y reiteró la solicitud de emprender investigaciones sobre su problema de la siguiente manera:

\begin{abstract}
"Me mueven a hacerle todas estas solicitudes mi amor por la labor docente, por el Colegio, por mis colegas y por mi Patria, además el temor que siento por las mentalidades de resentimiento que se pretende formar en los alumnos del colegio. Ruego a Usted si tiene a bien después de hacer estas investigaciones ver la posibilidad de nuestro reintegro como Profesoras del Colegio Andacollo y de entregar el establecimiento a personas idóneas que se dediquen realmente a la labor educativa y no a impartir líneas políticas contrarias a nuestro Gobierno e idiosincrasia chilena" (Ministerio de Educación Pública, 1983, p. 3).
\end{abstract}

En base a la revisión de las fuentes consultadas, es posible sostener que los efectos de esta carta delatora fueron amplios, puesto que consiguió movilizar la maquinaria de vigilancia y persecución política de manera rápida y efectiva. Esto es posible de visualizar claramente en el Documento Reservado $\mathrm{N}^{\circ}$ 210.275 enviado por el Director de la CNI, Mayor General Humberto Gordon Rubio, al Subsecretario de Educación Pública, Capitán de Fragata Juan Enrique Fröemel Andrade, el 24 de Febrero de 1983. En dicha comunicación es posible encontrar un informe de la investigación realizada por la misma CNI sobre las acusaciones esgrimidas contra el Colegio Andacollo, con especial énfasis en la figura de dos personas. La primera persona indagada fue justamente el Rector del Colegio Andacollo, Padre Gerald Richard Barmasse Linteo, de quien fue informado lo siguiente por parte del aparato represor:

“2. Este Sacerdote ha impuesto, en el Colegio Andacollo, una línea abiertamente izquierdizante. Se utiliza la asignatura de Religión para hacer una labor proselitista y de concientización entre los alumnos. Entre las actividades extraprogramáticas han realizado charlas con contenido político, las que se dan tanto a los alumnos como a padres y apoderados, siendo uno de los principales expositores el dirigente de la Coordinadora Nacional Sindical, MANUEL BUSOS HUERTA. En Noviembre de 1982 se realizó en el Colegio una exposición pública de pintura y dibujo donde se presentaron cuadros lesivos a la dignidad de S.E. el Presidente de la República” (Central Nacional de Informaciones, 1983, p. 2). 
La segunda persona apuntada por la CNI en su informe fue Luis Iván Salinas Melo, conceptualizado como integrante de un grupo de izquierda vinculado a la Iglesia Católica, además de tener relación con el MIR. Los demás antecedentes de esta persona proporcionados por la CNI fueron los siguientes:

“- En el Colegio Andacollo es conocido como agitador y concientizador. - Es el organizador de las exposiciones de pinturas que se realizan en el colegio. - Organiza y agita a los alumnos, mandándolos a las "marchas de hambre", realizadas en el centro de Santiago. - Ha colocado murales en el colegio, los que mirados de lejos muestran la bandera del "MIR" en sus colores rojo y negro, junto a algunas leyendas. - SALINAS MELO, organiza todos estos actos, pero luego se retira y no participa en ellos" (Central Nacional de Informaciones, 1983, p. 2).

Para finalizar, la CNI agregó a su informe una breve sugerencia, que apuntaba a extender el proceso de investigación sobre el Colegio Andacollo:

"Por tratarse de un colegio subvencionado por el Estado, se sugiere ordenar una inspección administrativa contable, con el fin de detectar irregularidades existentes, siendo causal de una drástica sanción" (Central Nacional de Informaciones, 1983, p. 2).

Con posterioridad, el 20 de Mayo de 1983, el Jefe Superior de Seguridad del Ministerio de Educación Pública, Coronel de Ejército Atiliano Jara Salgado, envió el Documento Reservado N²6 al Subsecretario de Educación Pública, Capitán de Fragata Juan Enrique Fröemel Andrade, informándole que en base a la sugerencia de la CNI se habría llevado a cabo una inspección al Colegio Andacollo por parte de la Secretaria Ministerial de Educación Región Metropolitana, teniendo como resultados que en lo técnico/pedagógico y en lo financiero/contable no había sido posible identificar irregularidades. No obstante, considerando todo el entramado de este caso, era necesario considerar los siguientes cursos de acción:

\footnotetext{
"No obstante, lo expuesto, se han impartido instrucciones a Secretaría Ministerial de Educación, Región Metropolitana, en el sentido que se disponga visitas inspectivas con cierta periodicidad al colegio mencionado para que fiscalicen y controlen el aspecto financiero, especialmente marquen centro de gravedad sobre las clases de Religión, diarios murales, Consejos de Curso, disciplina del alumnado, etc. Al respecto conviene señalar que la Oficina de Seguridad del Ministerio habiendo tomado debida nota de lo acontecido procurará en forma indirecta obtener otros antecedentes" (Ministerio de Educaciòn Pública, 1983, p. 1-2).
} 
Como es posible de observar, el efecto evidente de la carta delatora de la Profesora Normalista Lorenza Núñez Cabrera corresponde a la activación de la maquinaria de vigilancia y persecución política de la Dictadura Militar sobre el Colegio Andacollo y los integrantes de su comunidad.

Al considerar estas tres cartas de delación escritas por docentes es posible proponer algunas lecturas. Una primera, y en parte ya esbozada con anterioridad, es aquella que alerta sobre la necesidad de aceptar e indagar de manera más compleja y atenta la participación de la Sociedad Civil en las actividades de vigilancia, persecución y represión política desarrolladas por la Dictadura Militar. Tanto como existió resistencia a este fenómeno, también existió colaboración de personas comunes y corrientes en estas actividades. Sin posibilidades aquí de identificar motivaciones para entender estas colaboraciones, por lo menos el ejercicio de constatar aquello es importante, en términos de su aporte a la comprensión política de la Dictadura Militar y su capacidad de acción. Una segunda lectura posible, apunta a los tiempos en que dichas colaboraciones ocurrieron. Si bien las dos primeras cartas fueron redactadas y enviadas a pocos días transcurridos del Golpe de Estado del 11 de Septiembre de 1973, la tercera fue redactada y enviada en un momento en que la Dictadura Militar tenía más de 9 años de existencia. Este ejercicio de organización temporal de las cartas delatoras apunta finalmente a pensar en torno a los conocimientos y convencimientos que podrían tener los autores de las mismas con relación a aquello que la Dictadura Militar podría realizar factualmente contra sus opositores políticos. En palabras más simples: ¿Habrán sabido o no los docentes delatores que existían posibilidades ciertas de que sus acusados vieran sus derechos humanos amenazados a partir de sus acusaciones? ¿Sabían estos docentes delatores que el caer bajo la sospecha e indagación del aparato de represión podría tener serias consecuencias para sus acusados? Por lo menos, es complejo pensar que hacía inicios del año 1983, año en que se redactó y envió la tercera carta delatora, no se tuviese alguna dimensión de lo que la Dictadura Militar hacía con sus opositores políticos. Una tercera lectura posible, es aquella que apunta a la existencia entre las filas del profesorado, tal como en el resto de la sociedad chilena, de personas que simpatizaban, adherían y defendían a la Dictadura Militar, tanto en la dimensión de sus ideales políticos, como también en el plano de sus acciones factuales. ¿Cómo entender el amplio radio de acción de la Dictadura Militar en la persecución a sus opositores sin la ayuda de colaboradores de diferentes perfiles?

En el caso del profesorado este fenómeno es posible de ser apuntado en algunas situaciones interesantes. Una de estas, se relaciona con las preferencias partidarias que sostuvieron las profesoras y profesores en las elecciones de las directivas del Colegio de Profesores de Chile. Según los datos aportados por 
Cristián Cox y Cecilia Jara (1989) $)^{36}$ en los tres procesos electorales desarrollados durante la Dictadura Militar, a pesar de ser vencidas en términos generales, las listas de tendencia oficialista alcanzaron, de todas maneras, un porcentaje de la votación nada despreciable. En la elección de 1985 compitieron dos listas de docentes vinculados a la Dictadura Militar, las que tuvieron el siguiente desempeño: a) Unión Gremial de Educadores (UNIGED): 11.489 votos, equivalentes al 16,6\% del total de votos; b) Oficialista: 7.694 votos, equivalentes al $11,1 \%$ del total de votos. En la elección del año 1987 sólo se presentó una lista vinculada al Régimen, con el siguiente resultado: Unión Gremial de Educadores (UNIGED): 20.456 votos, equivalentes al 32,1\% del total de votos. Finalmente, también en la elección del año 1989 sólo se presentó una lista adscrita a la Dictadura Militar: Unión Gremial de Educadores (UNIGED): 19.396 votos, equivalentes al 30\% del total de votos. Si bien es necesario considerar las dificultades que tuvieron que enfrentar profesoras y profesores en sus espacios laborales y gremiales para poder expresar libremente sus adscripciones políticas y materializarlas al momento de emitir sus votos en estas elecciones del Colegio de Profesores, situación que imposibilita aceptar acríticamente el total de los votos emitidos a favor de las listas oficialistas, al mismo tiempo, es posible también pensar que parte importante de los mismos votos efectivamente fueron emitidos por profesoras y profesores vinculados políticamente a la Dictadura Militar.

Una segunda situación de adhesión de un sector del profesorado a la Dictadura Militar es posible de ser observada en una concurrida manifestación de apoyo de docentes al General Augusto Pinochet Ugarte en el contexto del desarrollo de la campaña que desembocaría finalmente en el Plebiscito Nacional del 05 de Octubre de 1988. Dicho Plebiscito tenía una altísima importancia, puesto que definiría la organización que asumiría el proceso de transición a la democracia en Chile ${ }^{37}$. En ese contexto de acumulación de fuerzas, quedó registrada en la Revista de Educación $\mathrm{N}^{\circ} 160$ de Septiembre de 1988 una nota ${ }^{38}$ sobre la manifestación de apoyo al General Augusto Pinochet organizada por parte de la denominada Asociación Gremial del Magisterio (AGREMA), oportunidad en que el Presidente de la República de Chile y Jefe Supremo de la Nación recibió la siguiente condecoración:

${ }^{36}$ Cox, C.; Jara, C. Datos básicos para la discusión de políticas en educación. 1970-1988. Santiago: CIDE / FLACSO, 1989, 74 p.

${ }^{37}$ En este Plebiscito, establecido en la Constitución Política de la República de Chile de 1980 como vía definitoria del proceso de transición a la democracia, la población chilena fue invitada a dirimir entre dos opciones: opción "Sí": que Augusto Pinochet Ugarte continuara en el poder por 8 años a partir del año 1989; opción "No": se abría paso un proceso de convocatoria a elecciones de Presidente de la República y de Diputados/Senadores, poniendo así fin a la Dictadura Militar. Finalmente ganó la opción "No", alcanzando un 55,99\% de preferencias en la votación.

${ }^{38}$ S/I. Presidente Pinochet recibe condecoración de profesores. Revista de Educación, Santiago, n. 160, p. 13, Septiembre 1988. 
"Por su destacada labor como docente de Historia, Geografía y Geopolítica y por ser el fundador de un nuevo Chile, la Asociación Gremial del Magisterio (Agrema) condecoró con la medalla Claudio Matte Pérez a S.E. el Presidente de la República, Capitán General Augusto Pinochet Ugarte” (S/I, 1988, p. 13).

Ciertamente, uno de los objetivos perseguido por esta publicación era el de resaltar el importante apoyo que supuestamente el profesorado habría expresado a Augusto Pinochet Ugarte en dicha actividad:

"La ceremonia se realizó en una multitudinaria manifestación de apoyo a la labor del gobierno y su obra, realizada el 11 de agosto en el Club Providencia de esa comuna de la Región Metropolitana, a la que asistieron más de dos mil profesores, quienes entusiasta y espontáneamente manifestaron su adhesión al Presidente Augusto Pinochet. Julio Luengo, Presidente de Agrema, refiriéndose al Presidente de la República señaló que 'es educador en el sentido profundo del formador de pueblos y por ser un estadista de talla excepcional" "' (S/I, 1988, p. 13).

A las diferentes manifestaciones de adhesión, más o menos entusiastas o espontáneas del profesorado asistente a esta actividad, Augusto Pinochet Ugarte destinó las siguientes palabras de agradecimiento, además de poner sobre la mesa conocidas promesas ad hoc para la ocasión:

"El Presidente Pinochet recordó con gran gratitud a su primera profesora, doña Raquel, y señaló que los profesores de Chile son los artífices del progreso, 'ser maestro -puntualizó- es mucho más que ser un simple profesional, porque tiene el futuro de la Patria en sus manos; porque se requiere mística, vocación de servicio, para que todo se haga por algo grande, por el bien de la Patria'. Asimismo manifestó el deseo expreso del Supremo Gobierno 'de poner todo el empeño necesario en aras de acrecentar más todavía la dignidad del profesor de Chile" " (S/I, 1988, p. 13).

En ese ambiente de solemnidad, camaradería y mutuo reconocimiento, coincidieron seguidores y líder. Confirmando adhesiones y simpatías forjadas por largos años de Dictadura Militar. En la sociedad chilena en general, al igual que al interior del profesorado, se había forjado una no despreciable coincidencia de intereses y visiones de mundo con el amplio proyecto de la Dictadura Militar. Todo esto a pesar de su estrategia de amedrentamiento, vigilancia, persecución, exclusión, tortura, destrucción y desaparecimiento de opositores políticos, fuesen estos quienes fuesen. 


\section{Palabras finales}

Considerando las fuentes analizadas en este trabajo es posible señalar que la violencia política hacia el Trabajo Docente durante la Dictadura Militar alcanzó características particulares, tanto en su magnitud como también en su lógica de funcionamiento, puesto que debe ser pensada con relación al espacio escolar y su especificidad. Fue posible constatar la existencia de graves violaciones a los derechos humanos de profesoras y profesores por parte de agentes del aparato de represión de la Dictadura Militar, incluyendo, por cierto, variados casos de docentes Detenidos Desaparecidos y Detenidos Ejecutados. Toda esta acción represiva dirigida hacía el Trabajo Docente, efectivamente asumió características muy particulares y sorprendentes. Primero; se sustentó en el poderío y capacidad técnica de complejas organizaciones de inteligencia y represión política, que contaban con amplias capacidades materiales y humanas para emprender sus actividades, tales como: sistemas de acumulación y procesamiento de información sobre opositores políticos de elaboradas características; sistemas de análisis y predicción del estado de la tensión social; disposición de recursos técnicos y contingentes de las Fuerzas Armadas y de Orden; entre otros. Segundo; se orientó con mayor violencia hacía un perfil de docente específico: mayoritariamente hombres jóvenes y de mediana edad; que sostenían una militancia política abiertamente reconocida; ser en su mayoría de nacionalidad chilena; ser desaparecidos y ejecutados de forma mayoritaria en los primeros momentos de existencia de la Dictadura Militar (1973-1974) y de manera más recurrente en la ciudad de Santiago. De esta forma, dentro de los variados análisis posibles de realizar aquí, es importante destacar el hecho de que la Dictadura Militar buscó decididamente atacar preferentemente a aquellas profesoras y profesores que se habían atrevido a vincular, dentro del espacio de su existencia, las dimensiones de ser docente y ser militante político, articulando complejamente a ambas en su diario vivir. Dicha combinación, tanto en el discurso como en la acción de la Dictadura Militar, se constituyó en un blanco predilecto de su furia represiva. Tercero; efectivamente el Trabajo Docente y sus especificidades, obligaron a la Dictadura Militar a desplegar todo un aparataje para encaminar y hacer viables sus tareas de represión y vigilancia hacía el profesorado. En dicha orientación, es importantísimo destacar el ejercicio realizado aquí en pos de contornear, aunque fuese mínimamente, la organización y funcionamiento de toda una estructura de represión y vigilancia, presente en Establecimientos Educacionales y en las instituciones de administración estatal del sistema educacional, a lo largo de Chile. Dicha estructura de represión y vigilancia, organizada y administrada por el aparato de represión de la Dictadura Militar, contó con el decidido apoyo de integrantes de la comunidad educacional (gestores, funcionarios, docentes, estudiantes, 
padres) a través de complejas redes de delación y espionaje. En las fuentes consultadas, la participación de integrantes de la Sociedad Civil en estas tareas es abrumadora y ciertamente merece nuevos estudios específicos y profundos para comprender sus características generales. Cuarto: también fue posible identificar la poderosa capacidad de influencia en el sistema educacional del aparato de represión de la Dictadura Militar, tanto a nivel de los amplios canales de comunicación y coordinación existentes entre importantes funcionarios públicos del Ministerio de Educación Pública y los líderes de los organismos de represión; como así también, a través de la existencia de complejos procesos de entrecruzamiento de usos y objetivos en las Políticas Públicas Educacionales dirigidas hacía el Trabajo Docente. Esto último tiene que ver con el descubrimiento alcanzado aquí con respecto a que importantes Políticas Públicas Educacionales diseñadas por la Dictadura Militar hacía el Trabajo Docente (Carrera Docente (1978-1981); Estatuto del Profesor (1986-1987)) con miras a reorganizar diferentes aspectos de la actividad laboral del profesorado, finalmente fueron diseñadas, modificadas e implementadas con el objetivo de facilitar y viabilizar, por vías institucionales, la persecución política dirigida hacía integrantes del profesorado identificados como opositores políticos. De esta forma, fue posible advertir la existencia de canales comunicantes entre las diferentes Políticas Públicas Educacionales de la Dictadura Militar, fuesen públicas o no públicas, invitando así a continuar investigando estos fenómenos vinculados a conocer de mejor manera los caminos superficiales y subterráneos que la Dictadura Militar transitó tras la búsqueda de sus objetivos. 


\section{Referencias bibliográficas:}

CHILE. Decreto Ley $\mathrm{N}^{\circ} 3$ Declara Estado de Sitio. Ministerio de Defensa Nacional - Subsecretaria de Guerra, Santiago, 18 Septiembre 1973. Disponible en: http://bcn.cl/1rwzr Consultado en: 14 Julio 2015.

CHILE. Decreto Ley $N^{\circ} 4$ Declara en Estado de Emergencia las Provincias y Departamentos que indica. Ministerio de Defensa Nacional - Subsecretaria de Guerra, Santiago, 18 Septiembre 1973. Disponible en: http://bcn. cl/1rx13 Consultado en: 14 Julio 2015.

CHILE. Decreto Ley $\mathrm{N}^{\circ} 81$ Fija, por razones de seguridad del estado, sanciones; para las personas que desobedezcan el llamamiento; público que indica del gobierno. Ministerio de Defensa Nacional - Subsecretaria de Guerra, Santiago, 06 Noviembre 1973. Disponible en: http://bcn. cl/1yjo5 Consultado en: 14 Julio 2015.

CHILE. Decreto Ley N 604 Prohíbe el ingreso de personas al territorio nacional en los casos que indica. Ministerio del Interior, Santiago, 10 Agosto 1974. Disponible en: http://bcn.cl/1weka Consultado en: 14 Julio 2015.

CHILE. Decreto $\mathrm{N}^{\circ} 890$ Fija texto actualizado y refundido de la Ley 12.927, sobre Seguridad del Estado. Ministerio del Interior, Santiago, 26 Agosto 1975. Disponible en: http://bcn.cl/1v181 Consultado en: 14 Julio 2015.

CHILE. Decreto $N^{\circ} 400$ Fija texto refundido, coordinado y sistematizado de la Ley $\mathrm{N}^{\circ} 17.798$, sobre control de armas. Ministerio de Defensa Nacional, Santiago, 13 Abril 1978. Disponible en: http://bcn.cl/1v2mw Consultado en: 14 Julio 2015.

CHILE. Decreto Ley N $N^{\circ}$.191 Concede amnistía a las personas que indica por los delitos que señala. Ministerio del Interior, Santiago, 19 Abril 1978. Disponible en: http://bcn.cl/1v3xd Consultado en: 14 Julio 2015.

CHILE. Decreto Ley $N^{\circ} 2.327$ Crea la Carrera Docente y regula su ejercicio. Ministerio de Educación Pública, Santiago, 22 Septiembre 1978. Disponible en: http://bcn.cl/3i2a Consultado en: 14 Julio 2015.

CHILE. Ley $\mathrm{N}^{\circ} 18.314$ Determina conductas terroristas y fija su penalidad. Ministerio del Interior, Santiago, 17 Mayo 1984. Disponible en: http://bcn. cl/1v1bp Consultado en: 14 Julio 2015.

COMISIÓN NACIONAL DE VERDAD Y RECONCILIACIÓN. Informe de la Comisión Nacional de Verdad y Reconciliación. Santiago: Secretaria General de Gobierno - Secretaría de Comunicación y Cultura, 1991, 2 Tomos 3 Volúmenes.

COMISIÓN NACIONAL SOBRE LA PRISIÓN POLÍTICA Y TORTURA. Informe de la Comisión Nacional Sobre la Prisión Politica y Tortura. Santiago: La Comisión, 2005. 777 p. 
COMISIÓN PRESIDENCIAL ASESORA PARA LA CALIFICACIÓN DE DETENIDOS DESAPARECIDOS, EJECUTADOS POLÍTICOS Y VÍCTIMAS DE PRISIÓN POLÍTICA Y TORTURA. Informe de la Comisión Presidencial Asesora para la Calificación de Detenidos Desaparecidos, Ejecutados Políticos y Víctimas de Prisión Política y Tortura. Santiago: La Comisión, 2011. 55 p.

CORPORACIÓN NACIONAL DE REPARACIÓN Y RECONCILIACIÓN. Informe Sobre Calificación de Victimas de Violaciones de Derechos Humanos y de la Violencia Política. Santiago: La Corporación, 1996. 635 p.

COX, C.; JARA, C. Datos básicos para la discusión de políticas en educación. 1970-1988. Santiago: CIDE / FLACSO, 1989, 74 p.

GARCÉS, M. Crisis social y motines populares en el 1900. Santiago: LOM, 2003. $258 \mathrm{p}$.

GARZÓN, E. "El terrorismo de Estado. (El problema de su legitimación e ilegitimidad)", en Revista de Estudios Políticos, Madrid, n. 65, p. 35-55, Julio-Septiembre 1989.

MANNS, P. Las grandes masacres. Santiago: Editora Nacional Quimantú, $1972.95 \mathrm{p}$.

RETAMAL, J. Nos siguen pegando abajo. Jaime Guzmán, dictadura, concertación y alianza: 40 años de educación de mercado. Santiago: Ceibo Ediciones, 2013, 87 p.

SÁNCHEZ, P. Una asignatura pendiente: profesores y profesoras detenidos/ as desaparecidos/as y ejecutados/as en Chile de 1973 a 1990. Santiago: Editorial ARCIS, 2013. 423 p. 